\title{
Article \\ A Comparative Analysis on Probability of Volatility Clusters on Cryptocurrencies, and FOREX Currencies
}

\author{
Usha Rekha Chinthapalli
}

check for updates

Citation: Chinthapalli, Usha Rekha. 2021. A Comparative Analysis on Probability of Volatility Clusters on Cryptocurrencies, and FOREX Currencies. Journal of Risk and Financial Management 14: 308. https://doi.org/10.3390/ jrfm14070308

Academic Editors: Jong-Min Kim and Shigeyuki Hamori

Received: 26 April 2021

Accepted: 24 June 2021

Published: 6 July 2021

Publisher's Note: MDPI stays neutral with regard to jurisdictional claims in published maps and institutional affiliations.

Copyright: (C) 2021 by the author. Licensee MDPI, Basel, Switzerland. This article is an open access article distributed under the terms and conditions of the Creative Commons Attribution (CC BY) license (https:// creativecommons.org/licenses/by/ $4.0 /)$.
Independent Researcher, H. No: 5-7-12, Housing Board Colony, Pakabanda Bazar, Khammam 507001, India; usha.bandu@gmail.com

\begin{abstract}
In recent years, the attention of investors, practitioners and academics has grown in cryptocurrency. Initially, the cryptocurrency was designed as a viable digital currency implementation, and subsequently, numerous derivatives were produced in a range of sectors, including nonmonetary activities, financial transactions, and even capital management. The high volatility of exchange rates is one of the main features of cryptocurrencies. The article presents an interesting way to estimate the probability of cryptocurrency volatility clusters. In this regard, the paper explores exponential hybrid methodologies GARCH (or EGARCH) and through its portrayal as a financial asset, ANN models will provide analytical insight into bitcoin. Meanwhile, more scalable modelling is needed to fit financial variable characteristics such as ANN models because of the dynamic, nonlinear association structure between financial variables. For financial forecasting, BP is contained in the most popular methods of neural network training. The backpropagation method is employed to train the two models to determine which one performs the best in terms of predicting. This architecture consists of one hidden layer and one input layer with $\mathrm{N}$ neurons. Recent theoretical work on crypto-asset return behavior and risk management is supported by this research. In comparison with other traditional asset classes, these results give appropriate data on the behavior, allowing them to adopt the suitable investment decision. The study conclusions are based on a comparison between the dynamic features of cryptocurrencies and FOREX Currency's traditional mass financial asset. Thus, the result illustrates how well the probability clusters show the impact on cryptocurrency and currencies. This research covers the sample period between August 2017 and August 2020, as cryptocurrency became popular around that period. The following methodology was implemented and simulated using Eviews and SPSS software. The performance evaluation of the cryptocurrencies is compared with FOREX currencies for better comparative study respectively.
\end{abstract}

Keywords: cryptocurrency; FOREX currencies; volatility clusters; volatility persistence; cryptocurrency market

\section{Introduction}

Volatility is commonly employed for estimating the distribution of returns on a given financial asset to assess financial market instability. The simulation and estimation of volatility, therefore, play a significant role in the management and pricing of derivatives (Kočenda and Moravcová 2019). Most of the time, own-currency volatilities explain substantial share of exchange rates movements. While volatility is not explicitly observed, several volatility measures are suggested. The dynamic of this "observed" volatility mechanism was then built to model and predict (Ramos-Pérez et al. 2019). For decades, different models of volatility were tested. Numerous models imitate major swings in cryptocurrencies and currencies; at the same time, smaller models are more prone to follow modest price fluctuations. The pattern of significant market swings in the financial asset is known as volatility clustering (Pongsena et al. 2018), resulting in these price shifts being permanent. In modelling volatility clusters, financial literature is relevant as the market conditions are considered a key market risk predictor. 
The amount of trade contains some commodities, including derivatives, making volatility their most important pricing factor, which increases over time. In the past several decades, the FOREX markets and their operations have changed dramatically. The days have passed when foreign exchange transactions are utilized in central banks, investment, and business. The presence of multinational businesses, private investors, speculators, hedge funds, individual investors, and arbitration companies in foreign exchange transactions has affected global and economic integration. From a conventional limited hour, the foreign exchange market has shifted operational structure to a 24-h electronic-based, market-oriented mechanism. With an estimated daily transaction of 3.2 trillion USD, this market is already considered the world's largest financial market. The aforementioned dynamics have endowed the FOREX market with a particular characteristic known as "volatility" (Ho et al. 2017). In controlling the exchange rate flutter and alleviating negative consequences of cross-market disruptions, i.e., currency markets and through commodity that could harm individuals and companies alike, especially for corporations and policymakers, modelling volatility exchanges across commodity and currency markets are especially relevant. Emerging markets are more susceptible to global shocks and lack an active derivatives market where market participants may hedge against currency risks are more concerned with this issue (Rognone et al. 2020). Different studies have added to the commodity currency nexus literature from several perspectives and have shown broad data from mature and developing economies with relevant impact on practitioners and policymakers. The variance is among the most significant parameters in several random processes for process recognition. In recent decades the association between sudden instability and crises has become stronger (Asai et al. 2020).

The comprehensive behavior of the financial series shows that the major fluctuations seem more clustered than minor ones, and big losses, for example, tend to lump more than major gains together (Catania and Proietti 2020). Appropriate calibration of uncertainty and market risk are among the most daunting problems facing businesses that have to handle their assets' inherent vulnerability or financial actions, for example, pension funds, banks, or insurers. During the 2007-2008 financial crisis, when market risk and volatility forecasting algorithms failed, this became even more apparent. Some possible hedging possibilities are discovered based on the computed correlations between the bitcoin market and other assets (Tan et al. 2019). At the same time, the time series conditional variance are calculated according to different model specifications of ARCH. When the market is in chaos, the daily price restriction mechanism acts as a circuit breaker. However, when it comes to the link between PLH (Price Limit Hits) and market volatility (Reus et al. 2020). The supporters claim that price limits are efficient for minimizing price volatility, as, after the limits hits, the system effectively interrupts order flow. The opponents maintain, however, that the PLH serve as a magnet for enticing more traders, resulting in greater price volatility.

In addition to returning causalities, the causal influence from currencies to commodities occurs in volatility cases, often suggesting major transmissions from currencies to danger. It became apparent that the distributed ledger might be used to reduce investment risk by increasing public understanding about Bitcoin, which is crucial for the exchange market (Altan et al. 2019). Many contemporary theories focus on conditional variance or volatility, which measures the degree of unexpected return shifts and may thus be thought of as a random variable in a stochastic process (Kim et al. 2019). The class of models, which have been widely analyzed in literature as risk models of several financial time series, is based on a univariate GARCH model. The accuracy of the volatility projections increases by giving kurtosis and skewness for longer maturity solutions (Belasen and Demirer 2019). Compared with the electronic central money generated by the bank systems or central banks (Samirkaş 2020), cryptocurrencies are decentralized and distributed. Blockchain Technology exercises control of this distributed system. Blockchain Technology (Dritsaki 2019) launches modern cryptocurrencies and verifies crypto puzzles decoding transactions. 
In many financial models, the main underlying assumption is the consistency of the model, but this assumption is generally not fulfilled because financial returns could include systemic breaks due to regulatory, operational, or technical changes and economic policy changes or significant macroeconomic shocks (Liu et al. 2020). Due to the variety of dynamics over time, the existence of disturbances influences the efficiency of forecasts. A method based on the modification of the estimate window for the prediction model can be employed to fix possible structural splits. This research explores the clustering of uncertainty in various properties, i.e., cryptocurrencies, and FOREX currencies. The financial assets are known to be cryptocurrencies, FOREX reserves, and currencies. This comparative study of the two financial properties would be demonstrated with the GARCH and the ANN models. Five days in advance are also expected for volatility, with value relative to real values. By measuring different indicators on the instability of financial markets, the findings of this analysis validate the key provisions of the principle of early detection of crisis.

This article has six sections; Section 1 dealt with introduction. Section 2 examines the review literature, and Section 3 outlines the statement of problems. Section 4 reflects on research methodology; Section 5 continues with results and discussion. The study of this research paper is concluded in Section 6.

\section{Literature Review}

The volatility of an asset, which determines the distribution of this variable's outcomes, plays a vital role in a variety of financial applications. Its key use is to quantify the consumer risk-benefit. Volatility is also an important price parameter for financial goods. Both modern models of option pricing are based on a price valuation volatility parameter. Volatility is also used in applications for risk control and fund management in general. In addition to the present valuation of the fluctuations of the controlled assets, financial institutions need to be able to predict their potential values. For institutions engaged in options trading and portfolio management, volatility forecasting is particularly relevant.

(Koosakul and Shim 2021) published a document analyzing the precision of some of the most shared volatility projections: historical models for volatility (including exponentially weighted motion average), the implicit models for volatility, and autoregressive and heteroskedastic models. The model's estimation accuracy is checked for the S\&P 500 price index, demonstrating the benefits and drawbacks of each model.

(Wen and Wang 2020) examined total and directional volatility connectedness in global foreign exchange (FX) markets. The variance decomposition approach was used to build a high-dimensional volatility network using 65 major currencies; the author includes the volatility overflow rate and LASSo-VAR methods. The empirical data show that the U.S. dollar and the Euro are large transmitters of volatility, whereas others, such as the Japanese yen and the British pound, are net receivers of volatility. In the volatility connectivity network, currencies are often categorized based on geoFigureical distributions. Total volatility links react dynamically to changes and growth in global economic fundamentals during moments of crisis.

(Maciel and Ballini 2017) introduced the range-based modelling of volatility to define and estimate return-based models of conditional volatility. It involves the inclusion of the range calculation defined as the distance among the maximum and the leased asset's prices within a time frame as an exogenous variable in General Autoregressive Conditional Heteroscedasticity (GARCH) models. It assesses whether range offers more knowledge about the intraday volatility mechanism and enhances estimation in comparison with GARCH-type approaches.

(Cho et al. 2020) proposed an effective worldwide currency portfolio that may considerably reduce the risk of an exogenous global equity portfolio. The Japanese yen, Swiss franc, the U.S. dollar, and Euro move in a way that is contrary to the international equities market. The relevance of safe currencies to optimum currency portfolios has risen in terms 
of foreign currency volatility in the U.S. stock market, and the impact of foreign exchange market volatility is greater than the impact on U.S. stock volatility.

(Su 2021) investigated the volatility spillover magnitudes and drivers in the FX market using the realized volatility measurements and the HAR. This verifies both the impact on meteor showers (e.g., interregional spillovers of volatility) and on heatwaves (e.g., spillovers of intraregional volatility). Market state variables contribute to more than half of the explanatory power in predicting conditional volatility persistence. With this model, that calibrates volatility persistence and spillovers conditionally on market states performing statistically and economically better. (Katusiime 2019) examines the influence of financial sector stability on commodity price volatility spillovers. Volatility spillover is investigated using the proposed techniques. Overall, the results of both the GVAR and MGARCH techniques indicate low levels of volatility spillover and market interconnectedness except during crisis periods, at which point cross-market volatility spillovers and market interconnectedness sharply and markedly increased. (Arellano and Rodriguez 2020) suggested the weekly data for stock and FOREX market returns, a set of MS-GARCH models are estimated for a group of high-income (HI) countries and emerging market economies (EMEs) using algorithms allowing for a variety of conditional variance and distribution specifications. In the Latam FOREX market, estimates of the heavy-tailed parameter are lower than in the HI FOREX market and some other stock markets. In the FOREX markets, when leverage effects may not present in single-state models such as MS-GARCH, however, this does not happen.

(Salisu et al. 2018) integrated the volatility spillovers and return in global FX markets using the world's six greatest traded currency pairs, specifically the Euro, Swiss, gopher, loonie, Aussie, and cable. The research also conducted a rolling analysis of samples to record secular and cyclical moves in world FX markets. This revealed that the largest traded currency pairings are interdependent in accordance with spillover indices. In addition, return spillovers exhibit mild trends and bursts while volatility spillovers exhibit significant bursts but no trends. Further, identify crisis episodes that seem to have influenced the recorded fluctuations in returns and volatilities of global FX markets. (Nikolova et al. 2020) introduced a novel technique for estimating the likelihood of volatility classes with specific attention given to cryptocurrencies. To this end, the researcher used the FD4 method to compute the Hurst exponent of the volatility sequence. A particular criterion was defined to compute whether there are fixed-size volatility clusters. As a commonly used metric to calculate long-term store stock markets, the self-similarity index was consolidated. The report on the development of the S\&P 500 self-similarity index, which was also introduced by (Segovia et al. 2019). It was exposed that the more often volatility changes are made (rather than normally falling into the index), the larger the exponent for self-similarity is and the more probable it is that clusters of volatility will form.

(Swapna et al. 2015) proposed modified cluster data sets for teaching-learning based optimization (MTLBO) without prior knowledge of the number of clusters. The proposed technique determines effectively how many clusters or partitions are used while the program is executing. The suggested procedure is confined to partial clusters inspired by the algorithm of the K-means. The findings achieved by MTLBO are compared with the traditional method of TLBO and conventional differential evolution (DE). The results reveal that, in terms of function evaluations and cluster validity measurements, MTLBO offers greater accuracy than the two others.

A worldwide model to forecast currency crises was offered by (Alaminos et al. 2019). It utilizes a sample of 162 nations that allows the geoFigureical variability of the warning signs to be taken into consideration. The approach utilized was deep neural decisions (DNDTs), a methodology based on decision-making trees carried out by deep neural learning networks, and it is frequently employed in prediction compared to other techniques. This approach has considerable potential to bring macroeconomic policy into line with the risks arising out of currency declines to maintain global financial stability. 


\section{Statement of Problem}

In terms of portfolio management, the configurations of the Volatility Clustering Effect play key roles in the fields of portfolio management, notably asset allocation. The financial literature is interested in modelling clusters of volatility, as the latter is seen as a major market risk signal. The volume of trade in some assets such as derivatives is increasing over time, and volatility is becoming their main value. Financial volatility submits two fascinating empirical regularities that apply to various assets, markets, and time scales: it is fat-tailed (more precisely power-law distributed) and it tends to be clustered in time. In this article, the cryptocurrencies are positioned by comparing their dynamic features with one traditional and widely accepted financial asset of FOREX currencies. The investigator's initial analysis is based on the daily starting and closing price for about four years based on five components: volatility, centrality, cluster structure, robustness and risk of cryptocurrencies and FOREX currencies. Based on the result obtained from the analysis, a comparative analysis of the two different financial assets has to be illustrated. Volatility is projected 5 days ahead, and values are compared to the real value in order to determine the performance of models for the prediction of volatility.

\section{Research Proposed Methodology}

The study's key aims are to compare the prediction effects on volatility between the hybrid GARCH and ANN models of cryptocurrencies and FOREX currencies. The research is focused on secondary data obtained on the websites concerned. Traded financial asset prices are taken into consideration. The data are obtained from online sources in this manuscript. Data are derived from the capitalization of cryptocurrency, from FOREX sector capitalization for FOREX currencies.

Figure 1 illustrates the architecture of the proposed predicting sequence. First, the value of the financial assets must be determined. The financial instruments customized for this study are Crypto-currency and FOREX Currencies. The sector reveals uncertainty in possible rates at prospective prices of adapted financial assets. Effective pricing is preferred for blockchain and currency. The top four cryptocurrencies and seven FOREX currencies are listed in the study. The time trend of returns must be estimated along with the pattern of return growth. The model analysis shows how well inflation is increasing or declining from 2017 to 2020.

The most significant use of the GARCH model is to calculate regular returns. However, this GARCH model provided a strongly asymmetrical financial asset. Meanwhile, more scalable modelling is needed to fit financial variable characteristics such as ANN models because of the dynamic, nonlinear association structure between financial variables. The main value of ANN is its ability to model complex nonlinear relations without a prior assumption of their existence. A collection of entry variables can be correlated with one or more performance targets, which contain latent nonlinear units to ensure considerable stability. The pattern parameters are modified to ensure that the parameter tuning is accomplished via the quadratic loss function during the model estimation process. The lowest mistake, therefore, is iteratively calculated. In the final stage, findings from the above method determine the comparison of volatility clusters that occur on the financial asset. 


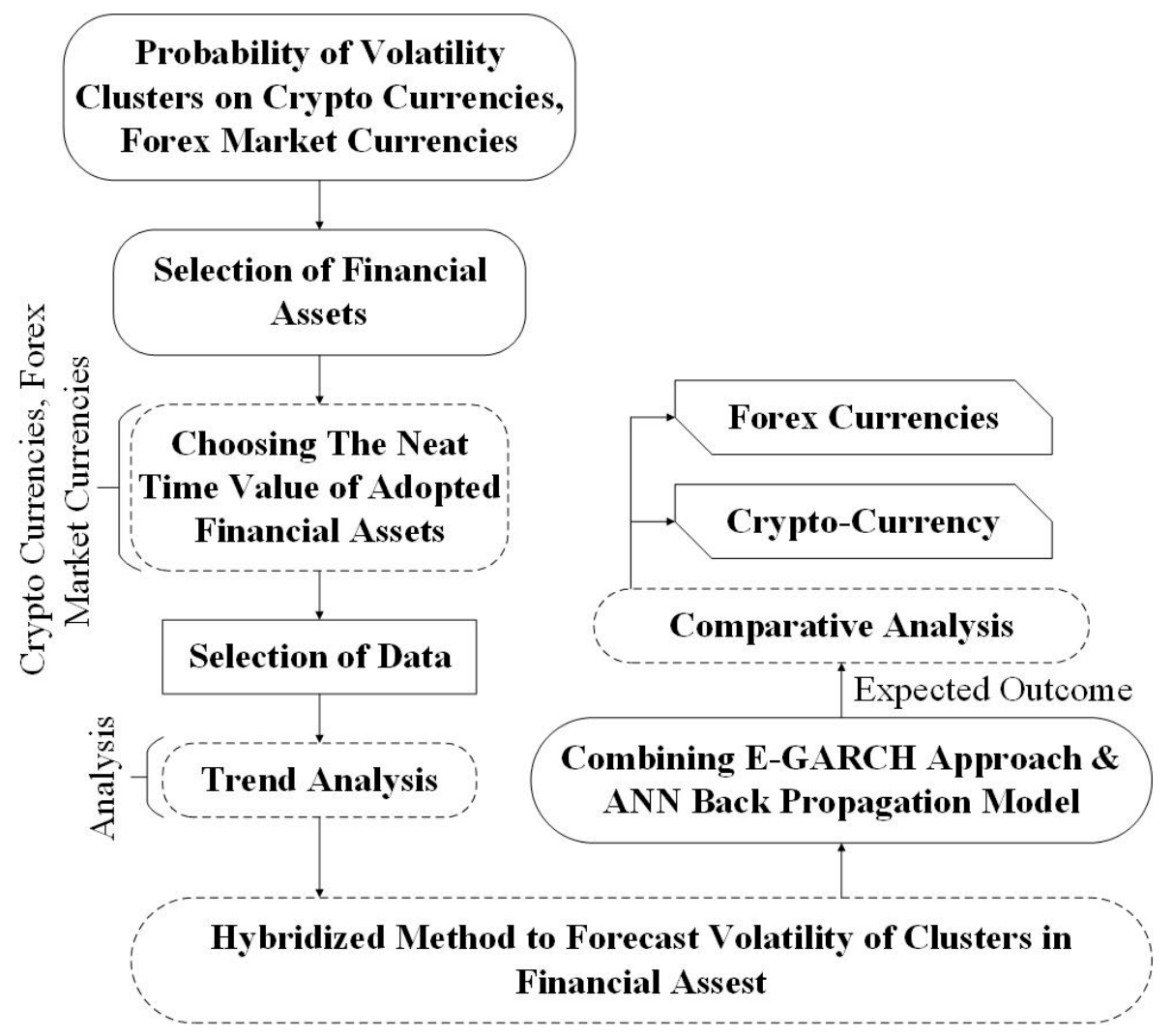

Figure 1. Architecture of Research Forecasting Model.

\subsection{Volatility Time Series}

Depending on prior knowledge (conditional), the time series depend on their past value (autoregressive) and are shown (heteroscedasticity). The FOREX market volatility was found as changing with time (i.e., "time variation"), with clustering of volatility. Interestingly, the associated volatility exponent for self-similarity was discovered to increase when high (resp., low) volatility clusters emerge in the series (resp., decreases). The volatility exponent therefore would be approximately 0.5 . On the contrary, assume that there are some high volatility clusters in the series (resp., low). Therefore, nearly every value in the volatility series is higher (or lower) than the series mean. Consequently, the volatility series has increased (or decreased), with the result that it rises in self-similarity as well (resp., decreases).

The major methods used for volatility modelling are the GARCH models. To record the volatility in the return series, GARCH methods are utilized. These models are frequently utilized in several fields of economic technology, particularly in the study of financial time series. In addition, numerous empirical uses of modelling variance (volatility) of the financial time series were introduced using the arch and GARCH models. Nevertheless, the GARCH could use leverage effect, which in one series represents a clustering of volatility and leptokurtosis. This required the creation of new and extended models over GARCH, which resulted in new models with the E-GARCH Approach and ANN Backpropagation Combination model.

\subsection{E-GARCH Model}

A conditional volatility model that can accommodate asymmetry is the EGARCH model of (Nelson 1991). The possibility that EGARCH may be made of a random coefficient of nonlinear moving average (RCCNMA), in particular EGARCH (1), has been proven by (McAleer and Hafner 2014). Similar to the TGARCH, the exponential GARCH model developed by Nelson is to capture consequences of leverage of shock (policies, information, news, incidents, and events) on the financial market. It allows for the testing of asymmetries. 
With good (bad) news, assets tend to enter a state of tranquility (turbulence), and volatility decreases (increases). This is done with the log of the variance series.

One of the most common univariate asymmetric conditional volatility models is an exponential GARCH (or EGARCH) formulation. EGARCH may additionally accept leverage, the negative correlation between shocks in return and subsequent shocks. In addition to asymmetry, which captures the different effects on conditional volatility of positive and negative effects of equal magnitude, EGARCH can also accommodate leverage, which is the negative correlation between returns shocks and subsequent shocks to volatility. Depending on the proper limitations on model parameters, the EGARCH model can capture leverage. Let the conditional mean of financial returns be given as

$$
y_{t}=E\left(y_{t} / I_{t-1}\right)+\varepsilon_{t}
$$

where $y_{t}=\Delta \log P_{t}$ reflects the $\log$ difference in the price of FOREX, $\left(P_{t}\right), I_{t-1}$ is the data set at one moment, $t-1$ and $\varepsilon_{t}$ is heteroscedastic conditionally.

The EGARCH conditional variance $(p, q)$ model is specified as:

$$
\log \left(h_{t}\right)=\psi+\sum_{i=1}^{q} \eta_{i}\left|\frac{u_{t-i}}{\sqrt{h_{t-i}}}\right|+\sum_{i=1}^{q} \lambda_{i} \frac{u_{t-i}}{\sqrt{h_{t-i}}}+\sum_{k=1}^{p} \theta_{k} \log \left(h_{t-k}\right)
$$

LHS is the series log of variance $\left(h_{t}\right)$, which makes the leverage effect exponential rather than quadratic. This assures non-negative estimations. $\phi=$ constant, $\eta=\mathrm{ARCH}$ effects, $\lambda=$ asymmetric effects and $\theta=$ GARCH effects.

If $\lambda_{1}=\lambda_{2}=\cdots=0$ the model is symmetric.

However, if $\lambda_{i}<0$ it signifies terrible news (negative shocks) and generate large volatility then good news (positive shocks).

\subsubsection{Estimation Results}

The daily time-series data representing the capital market returns engaged in this training is obtained from Stock Exchange Reports for a certain period. The choice of the EGARCH framework is to accommodate the examination of conditional variance (volatility), asymmetric effect, and volatility persistence. The model for volatility using the EGARCH framework is specified as follows:

$$
\vartheta_{t}^{2}=\omega+\beta_{i n} \vartheta_{t-1}^{2}+\alpha\left[\frac{\in t-1}{\vartheta t-1}-\frac{2}{x}\right]+\gamma\left|\frac{\in t-1}{\vartheta t-1}\right|
$$

where, $\omega, \beta, \alpha, \gamma$ are parameters constant. In $\vartheta_{t}^{2}$ is the one-term anticipation of volatility, and $\omega$ refers to the mean level, $\beta$ is the parameter of persistence and $\alpha$ is the volatility clustering coefficient. Similarly, $\vartheta_{t-1}^{2}$ is the past variance and $\gamma$ is the leverage effect.

The EGARCH-in-mean model is a GARCH enhancement that imposes non-negativity constants on a market variable and enables a conditional variance to respond to innovations of various signs asymptomatically. If $\gamma$ is negative, a leverage effect exists, implying that the bad news is more volatile than good news than expectations of similar magnitude. The negative value $\gamma$ is often mentioned as the sign effect. If $\alpha$ positive, conditional volatility increases if the total value of the standardized residuals is greater (smaller). Where, $\alpha$ is the impression of magnitude. Interestingly, for related volatility series, the self-similarity exponent increases as high as (resp., low) volatility clusters are replaced by series (resp., decreases).

\subsubsection{Calculation of the Volatility Cluster Probability}

This section investigates how the volatility clusters may be evaluated for blocks of a certain size. The Hurst Exponent is usually regarded as a reliable indicator of the presence of trends. This exponent computation for each technique yields a different result as the period utilized and the length of underlying subintervals increase. As a consequence, 
finding a unique Hurst exponent value is unattainable; therefore, calculating a unique critical value is impossible.

Thus, Brownian Motion's Hurst exponent volatility series is implied as a standard to determine if the series contains a volatility cluster. Clusters match nicely with given sectors including economic taxonomy (such as business sectors of the companies provided by Forbes) and geoFigureical region (such as Asia and Europe). It may also detect assets from clusters that are actively at work and dominate financial markets effectively. The market activity might cause cluster changes. Here, I analyze how asset nodes are clustered and analyze the evolution of clusters in the financial markets

More specifically, a set of Brownian movements was produced first via Monte Carlo simulation. The exponents of their respective volatility ranges shall be computed for every Brownian motion. The exponent of Hurst is greater than $H_{\text {lim }}$ for the corresponding volatility series as volatility clusters exist in the series. Then, measure the probability of volatility clusters for subseries of a given length as the ratio between the number of subseries with volatility clusters to the total amount of subseries of the given length. I test it using artificial processes with volatility clusters to verify the likelihood of the clusters of volatility.

\subsection{Artificial Neural Networks}

A huge nonlinear dynamic system, capable of carrying out extremely nonlinear, selflearning and self-organizing operations, is an Artificial Neural Network (ANN). This experiment employs the most frequently exploited business network, a neural background network.

\subsubsection{Backpropagation Neural Networks}

The backpropagation mechanism evaluates the weights of the connections between the nodes in accordance with data formation results. This forming a minimized least mean-square error measure of the actual, required, and estimated values from the output of the neural network. Figure 2 depicts a three-layer backpropagation neural network. Initial values are assigned to the connection weights. In addition, an error has backpropagated across a network to update weights between the actual and the expected output values. The monitored training process ensures that the mistake between the intended results and the forecast is minimized.

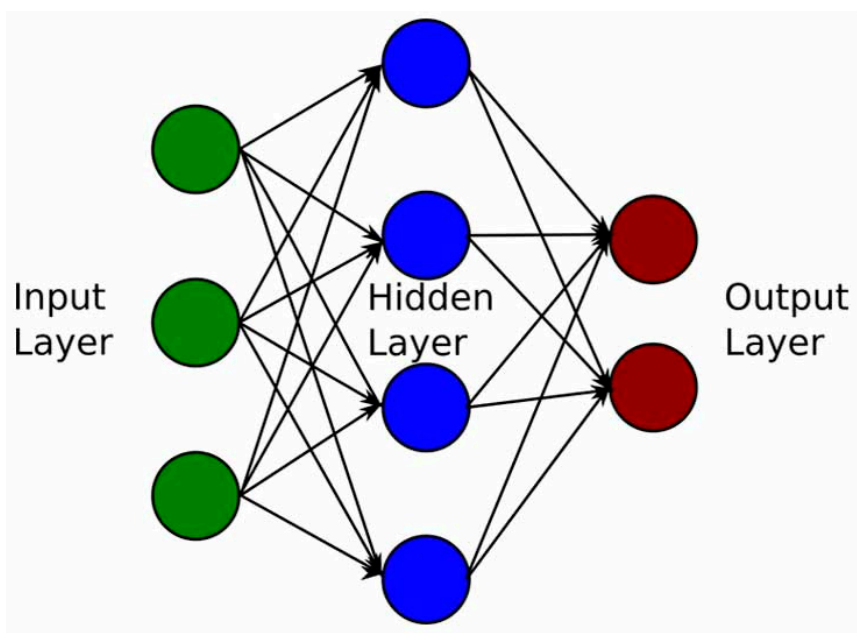

Figure 2. Supervised Learning Back Propagation Neural Network.

Theoretically, neural networks can imitate any data patterns with adequate training. Before applying for predicting, the neural network must be trained. The neural network is built on experience throughout the training phase based on the provided hypotheses. For each neural network model, a hidden layer is used and the sigmoid function is the activation function. 
The BP-ANN training is as follows:

Backpropagation is a supervised learning algorithm, for training Multilayer Perceptron's (Artificial Neural Networks). Let $\operatorname{In}(n)$ and $\mathrm{Out}(n)$ identify correspondingly the node input and output, as follows:

$$
\begin{aligned}
& I n_{n}=\sum_{m} w_{m m} \mathrm{Out} t_{m} \\
& \mathrm{Out}_{n}=f\left(\operatorname{In}_{n}+\beta_{n}\right)
\end{aligned}
$$

where, $w_{n m}$ denotes the connecting weight from the $m$ th node in the last node layer $n$, and

$$
f(n e t)=\left(2 / 1-e^{-2 n e t}\right)-1
$$

This signifies the node activation ("net" is the net input of the neuron), which causes nonlinearity to the neuron output, while $\beta_{n}$ is the bias input to the node of a specific unit with an active, consistent, nonzero value connection weight. The output error $E$ is computed as follows:

$$
E=\frac{1}{2 N} \sum_{N} \sum_{o}\left(P_{N o}-O u t_{N o}\right)^{2}
$$

where $N$ and $o$ indicate the number of training items and the number of neurons in the output layer, respectively. The target $P_{N o}$ and output values $O u t_{N o}$ are represented accordingly. The training terminates if the error $E$ falls below the threshold or degree of tolerance. This is the result of the error $e_{0}$ in the output layer and the error $e_{n}$ in the concealed layer:

$$
\begin{gathered}
e_{0}=\lambda\left(P_{O}-O u t_{o}\right) f^{\prime}\left(\mathrm{Out}_{o}\right) \\
e_{n}=\lambda \sum_{m} e_{0} w_{m m} f^{\prime}\left(\mathrm{Out}_{n}\right)
\end{gathered}
$$

where the oth output node, real output in the output layer, current output in the hidden layer, $P_{o}, \mathrm{Out}_{o}, \mathrm{Out}_{n}$ and $\lambda$ is anticipated to represent the output node and the activation function adjustable variable, respectively. It is worth noting that $f^{\prime}$ signifies the derivative of $f$. Error backpropagation is used to update the weights $w_{m m}$ and biases $\beta(n)$ in both the output and hidden layers. The following equations are used to modify the weights and biases:

$$
\begin{gathered}
w_{n m}(k+1)=w_{n m}(k)+\gamma e_{0} O u t_{m} \\
\beta_{m}(k+1)=\beta_{m}(k)+\gamma e_{m}
\end{gathered}
$$

where the epoch number and the learning rate are denoted by $k$ and $\gamma$, respectively. Neural networks are successful in forecasting very volatile financial variables that are difficult to anticipate using traditional statistical approaches, such as exchange rates and interest rates, according to empirical study.

\subsubsection{Hybrid Methodology (E-GARCH-NN)}

The system aims to incorporate the E-GARCH volatility method into neural networks (ANNs) that provide the functional flexibility to collect nonlinearity in financial information. First, the GM $(1,1)$-GARCH model's forecasting feature is used to continuously change the sequence of squared error terms. In addition, several estimated volatility methods are used for estimating the volatility, which is used to evaluate the performance of option-pricing models with the backpropagation ANN model.

The model is specified as NN-EGARCH

$$
\log \sigma_{t}^{2}=\alpha+\sum_{i=1}^{p} \beta_{i} \log \sigma_{t-1}^{2}+\sum_{j=1}^{q} \gamma_{j}\left[\delta(\varepsilon / \sigma)_{t-j}+\left|(\varepsilon / \sigma)_{t-j}\right|-\sqrt{z / \pi}\right]+\sum_{h=1}^{s} \xi_{h} \psi\left(z_{t} \lambda_{h}\right)
$$




$$
\begin{gathered}
\psi\left(z_{t} \lambda_{h}\right)=\left[1+\exp \left(\lambda_{h, d, w}+\sum_{d=1}^{1}\left[\sum_{w=1}^{m} \lambda_{h, d, w} Z_{t-1}^{w}\right]\right)\right]^{-1} \\
z_{t-d}=\left[\varepsilon_{t-d}-E(\varepsilon)\right] / \sqrt{E\left(\varepsilon^{2}\right)} \\
(1 / 2) \lambda_{h, d, w} \sim \text { uniform }[-1,+1]
\end{gathered}
$$

$\sigma_{t}^{2}$ is a function asymmetric of $\varepsilon_{t}, \log \sigma_{t}^{2}$ indicates natural logarithms, $\psi\left(z_{t} \lambda_{h}\right)$ and $z_{t-d}$ is defined in Equations (12) and (13). The model utilizes a logarithmic design and square bracket terms to take into consideration the asymmetrical $\log \varepsilon$ effects.

The conditional variance is not negative as a result of the logarithmic transformation. This study evaluates which model best represents financial time-series features and better predicts their future behavior since this allows market participants to decide on the projected future values. This study contributes to the direction by comparing the performance of the conventional E-GARCH model with the performance of the backpropagation neural network model in forecasting conditional variance of FOREX returns using cluster probability for currencies and cryptocurrencies.

The research study can be evaluated with a wide range of real-time data. The data results must be noted and plotted for the analysis of the performance. The following methodology can be implemented and simulated on R-software or SPSS software, and the performance of the cryptocurrencies is compared with FOREX currencies for better comparative study, respectively.

\section{Results and Discussion}

\subsection{Data and Preliminary Analysis}

The cryptocurrency data were composed of 2017 daily closing prices for the period of 1 August 2017 to 31 August 2020. Almost all past research in this subject has focused on Bitcoin. This research focused on four cryptocurrencies: Ripple (XRP), Bitcoin, Ethereum, and Tether, which have the highest market capitalizations and a long history of data. These currencies and corresponding currency codes are listed in Table 1.

Table 1. Cryptocurrencies.

\begin{tabular}{cc}
\hline Currency Name & Currency Code \\
\hline Bitcoin & BTC \\
\hline Ripple & XRP \\
\hline Ethereum & ETH \\
\hline Tether & USDT \\
\hline
\end{tabular}

The top seven currencies were also taken for the study. The FOREX market operates $24 \mathrm{~h}$ a day, 5 days a week where the different trading sessions of the Europe-an, Mexican, Australia, British, Brazilian, Saudi Arabia, and Japanese FOREX markets take place. The nature of FOREX trading has resulted in a high frequency market that has many changes of directions, which produce advantageous entry and exit points. The FOREX market is almost active the entire day, with price quotes rapidly changing. These FOREX currencies and their currency codes are listed in Table 2.

Figure 3 illustrates the FX currencies return trajectories of the considered markets. Figure 3a states the time series of Australia. The Australian dollar shows a significant decrease in the middle of 2017, which broke through this range into the close of August with price quickly ducking back below in, early September trade. In 2020, the trend for the Australian dollar is rising, Australian dollar to average above 75 cents against the US dollar in 2020, about 5 cents higher than in 2019. Figure $3 \mathrm{~b}$ portrays the Brazilian real time series. The Brazilian real illustrates the significant influence between the year 2019 and 
2020. At the end of November 2020, one U.S. dollar could buy approximately 5.34 Brazilian reals, approximately 1.7 pesos more than at the beginning of 2019.

Table 2. FOREX Currencies.

\begin{tabular}{cc}
\hline Currency Name & Currency Code \\
\hline Euro & EUR \\
\hline Australian Dollars & AUD \\
\hline Mexican Peso & MXN \\
\hline British Pound & GBP \\
\hline Brazilian Real & BRL \\
\hline Saudi Riyal & SAR \\
\hline Japanese Yen & JPY \\
\hline
\end{tabular}

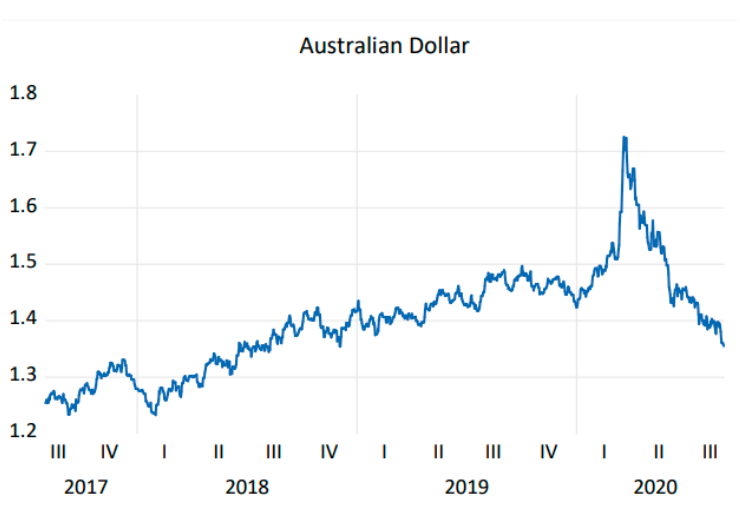

(a) Australian Dollar

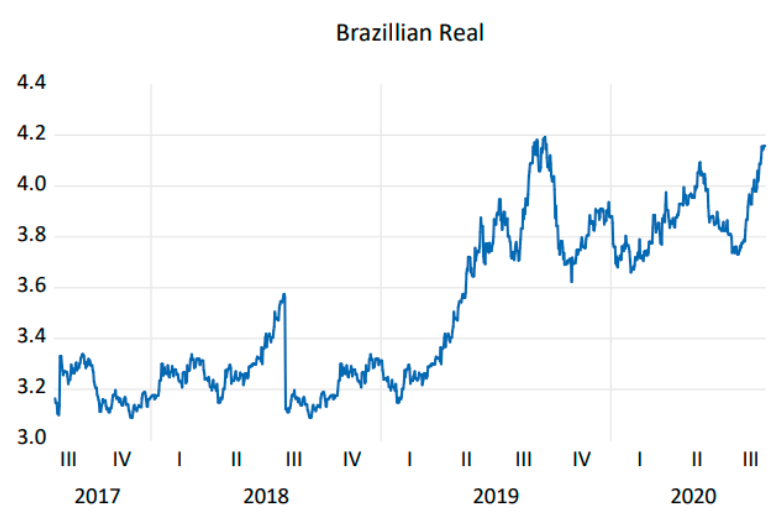

(b) Brazilian Real

Figure 3. Daily time series of FOREX currencies with Australian dollar and Brazilian real.

Figure 4a states that the British pound varies in time series in the years 2017-2020. It has a significant decrease in 2017-2018. Further, Figure $4 \mathrm{~b}$ denotes the Euro, which has a high impact in the year 2020. Figure 4c states the time series of the Mexican peso; it implies that from 2017-2019 there is a decrease in production except in 2020. Figure $4 \mathrm{~d}$ depicts the Saudi riyal time series. It shows that it looks like parallel production in the years 2017, 2018 and 2019. In comparison, the effect in 2020 is less significant.

\subsection{Descriptive Statistics}

The descriptive statistics of foreign currencies are provided in Table 3 to define the distributional characteristics of the daily return series of financial assets throughout the research period. Table 3 examine the descriptive statistics in terms of the standard deviation $(\mathrm{SD})$, mean $(\mathrm{X})$, kurtosis $(\mathrm{K})$, and skewness (S), of the data. The data demonstrate that in all cases, the returns are positively skewed rather than regularly distributed (except for the Mexican peso, Australian dollar and Saudi riyal). Furthermore, the calculated kurtosis was significantly greater than the normal distribution's value, indicating that the data had fewer than three in kurtosis. This means that it is dispersed normally. 
British Pound

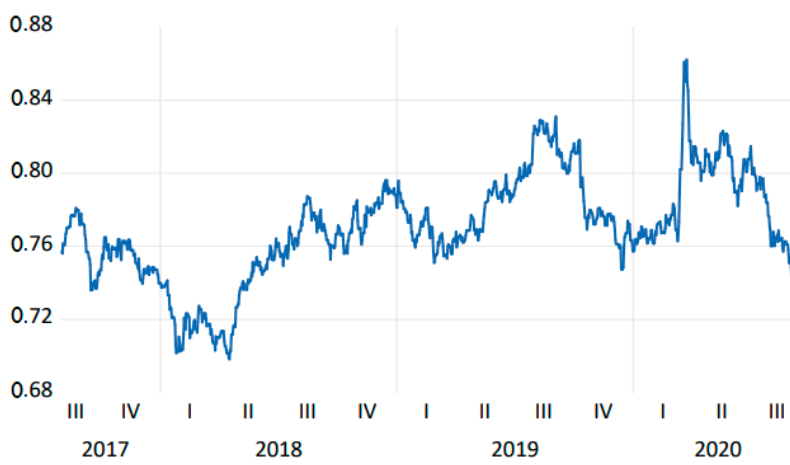

(a) British Pound

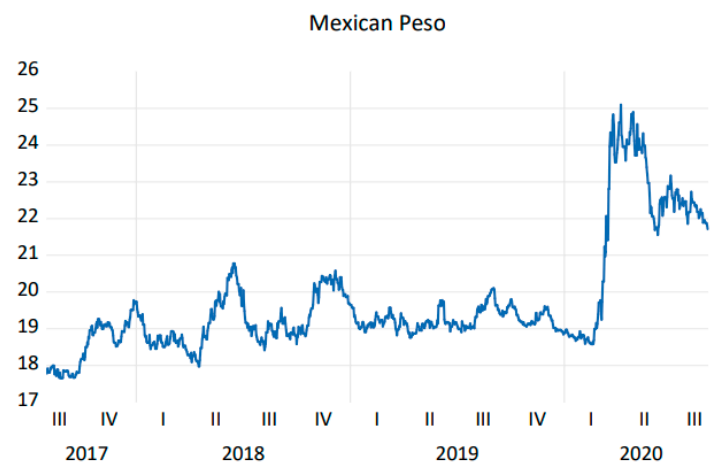

(c) Mexican Peso
EUR

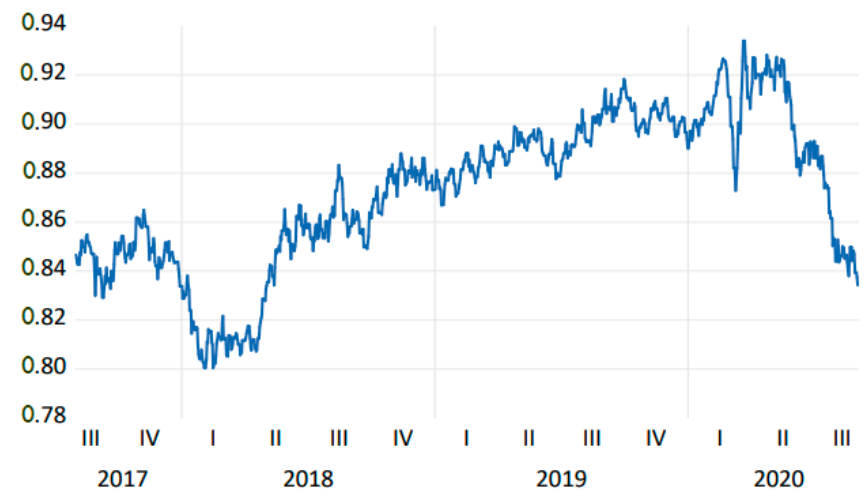

(b) European EURO

Saudi Riya

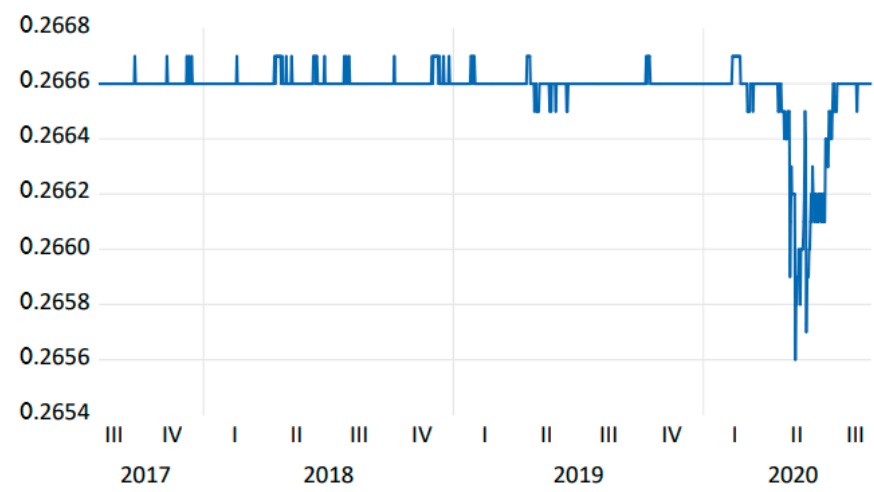

(d) Saudi Riyal

Figure 4. Daily time series of British pound, Euro, Mexican peso and Saudi riyal.

Table 3. Descriptive Statistics for FOREX Currencies.

\begin{tabular}{cccccccc}
\hline & Mean & Median & Maximum & Minimum & Std. Dev. & Skewness & Kurtosis \\
\hline Euro & 0.872696 & 0.8787 & 0.934 & 0.8004 & 0.031099 & -0.39 & -0.62 \\
\hline Mexican Peso & 19.70841 & 19.16075 & 25.1039 & 17.6529 & 1.548699 & 1.64 & 1.98 \\
\hline British Pound & 0.770294 & 0.76865 & 0.8622 & 0.6982 & 0.028363 & -0.11 & 0.18 \\
\hline Australian Dollars & 1.397557 & 1.40225 & 1.7253 & 1.2328 & 0.089557 & 0.44 & 0.46 \\
\hline Japanese Yen & 109.5859 & 109.4716 & 114.193 & 102.2346 & 2.291237 & 0.03 & -0.81 \\
\hline Brazilian Real & 3.506903 & 3.325 & 4.1935 & 3.0889 & 0.319262 & 0.39 & -1.36 \\
\hline Saudi Riyal & 0.266577 & 0.2666 & 0.2667 & 0.2656 & 0.000121 & -4.37 & 21.15 \\
\hline
\end{tabular}

\subsubsection{Volatility Clustering}

Volatility is frequently estimated by the variance and default. The standard deviation is the square root of the difference. With volatility persistence, volatility can shift expectations on the stock market, with more uncertainty affecting investors' decisions and desire to investors because of risk exposure. Figure 5 shows the movements of daily market returns of Bitcoin currency and traditional asset classes (equities, bonds, and cash) in the U.S. market. Accordingly, Figure 5a denotes the return series of the FOREX market. This is exhibiting volatility clustering persistence in their daily market returns. Figure $5 \mathrm{~b}$ states the return series of cryptocurrency bitcoin. This because their daily market returns series volatility changes with time, or in other words, it is time-varying. 
RETURN
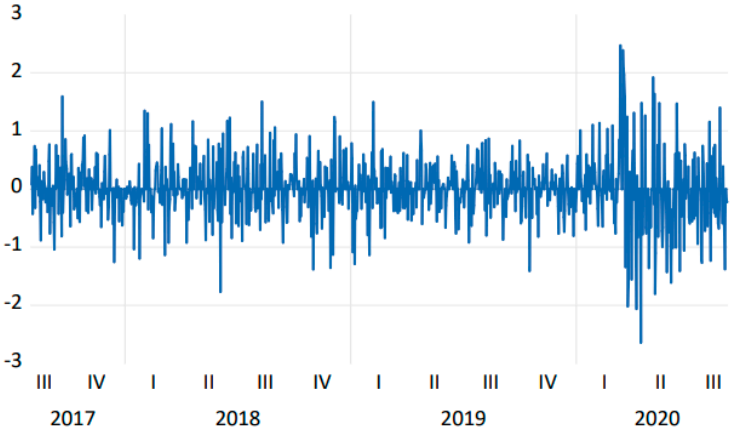

(a) FOREX Market

RETURN

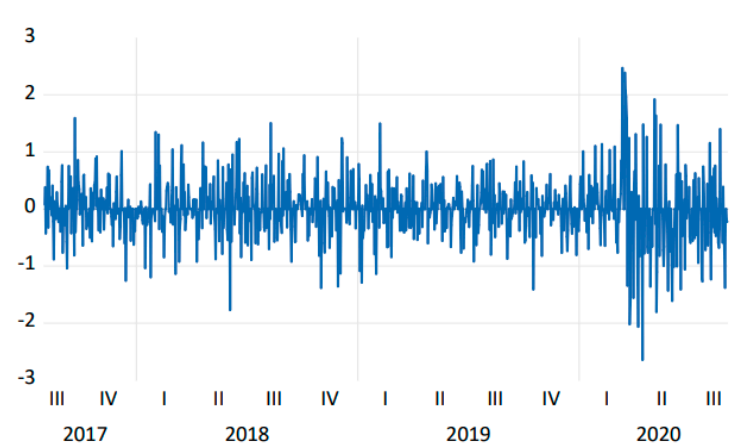

(c) Australian Dollar

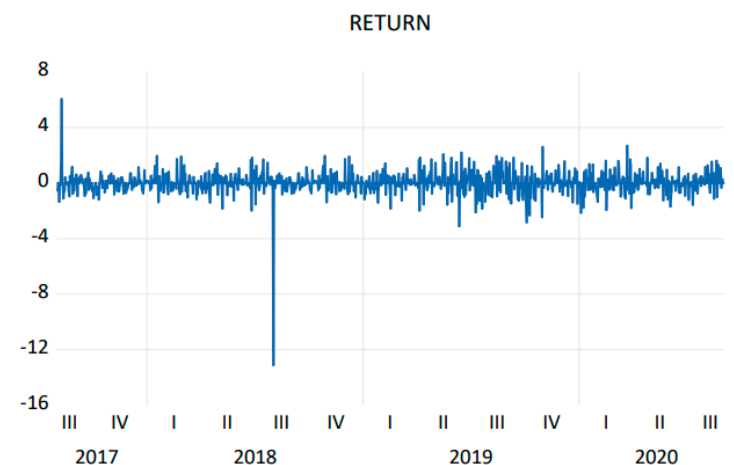

(b) Bitcoin RETURN

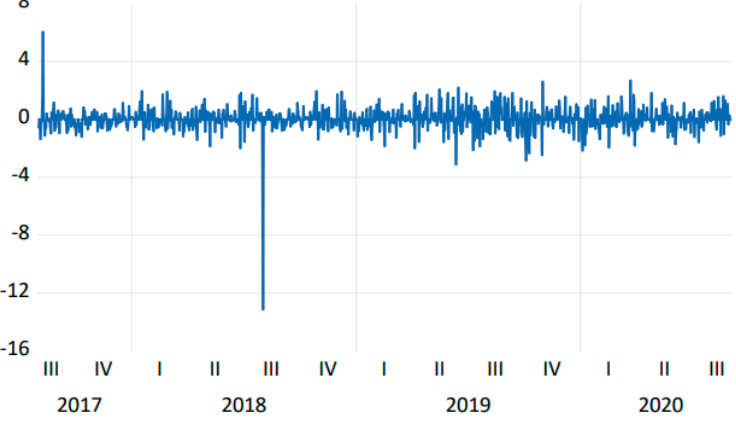

(d) Brazilian Real

Figure 5. Volatility of FOREX Currencies.

Figure $5 \mathrm{c}$ illustrates the volatility clustering of the Australian dollar. Subsequently, Figure $5 \mathrm{~d}$ states the Brazilian real volatility time series of FOREX currencies. The objective of the work is to determine the optimal GARCHGARCH model for the return series after the clustering of volatility is validated using stationarity and return series using ADF, heteroscedasticity, and pp test, and impact using the arch-lm test. As a result, in the FOREX market, the GARCH model is employed to represent the return series volatility.

Table 4 shows the results of GARCH $(1,1)$ models, revealing that the GARCH parameter is significant statistically. In other words, at the 0.05 percent level, the coefficients constant $(\omega)$, arch term $(\alpha)$, and GARCH term $(\beta)$ are very significant. The calculated coefficient in the conditional variance equation is much larger than $\alpha$.

\subsubsection{Augmented Dickey-Fuller (ADF) Test Coefficient Analysis}

The ADF is a unit root stationarity test. In a time-series analysis, unit roots can provide unpredictable results. With serial correlation, the ADF test may be employed. This test is more powerful and can handle more complicated models than the Dickey-Fuller test.

Figure 6 states the unit root test of ADF test analysis in the regression model of coefficients with the null hypothesis. Figure $6 \mathrm{a}, \mathrm{b}$ states the Dickey-Fuller autoregressive coefficients for FOREX currencies of the Australian dollar and Brazilian real, respective-ly. Figure $6 \mathrm{c}$ depicts the unit root test for the British Pound and illustrates the Dickey-Fuller test. This illustrates the Dickey-Fuller test with the least square support vector regression between the sample of 1 August 2017 to 31 August 2020. It contains Durbin Watson statistics with a better coefficient of 0.871. Figure 6d states the Dickey-Fuller (ADF) test of Euro in the regression model of coefficients with 0.976. Instantaneously, Figure 6e states the Dickey-Fuller autoregressive coefficients for the Japanese yen, which relies on a regression model with Durbin Watson statistics of 0.909 coefficient. Figure 6f,g illustrates the DickeyFuller autoregressive coefficients for the Mexican peso and Saudi riyal, respectively. The 
Mexican peso was tested with the sample R-Square and contains Durbin Watson statistics with a better coefficient of 0.453 .

Table 4. Estimated Result of GARCH $(1,1)$ Models.

\begin{tabular}{|c|c|c|c|}
\hline & \multicolumn{2}{|c|}{ Coefficient } & \multirow{2}{*}{$\begin{array}{c}\text { GARCH (1,1) } \\
0.87\end{array}$} \\
\hline \multirow{5}{*}{ Euro } & $\begin{array}{l}\text { Mean } \\
\text { (constant) }\end{array}$ & $\mu$ & \\
\hline & Variance & $\alpha 0$ & -308.28 \\
\hline & $\alpha 1$ & & 8574.48 \\
\hline & $\gamma 1$ & & 8574.48 \\
\hline & $\beta 1$ & & 90.12 \\
\hline \multirow{5}{*}{ Mexican Peso } & $\begin{array}{r}\text { Mean } \\
\text { (constant) }\end{array}$ & $\mu$ & 19.71 \\
\hline & Variance & $\alpha 0$ & 6712.63 \\
\hline & $\alpha 1$ & & $85,635.13$ \\
\hline & $\gamma 1$ & & $85,635.13$ \\
\hline & $\beta 1$ & & $40,008.81$ \\
\hline \multirow{5}{*}{ British Pound } & $\begin{array}{l}\text { Mean } \\
\text { (constant) }\end{array}$ & $\mu$ & 0.77 \\
\hline & Variance & $\alpha 0$ & 0.37 \\
\hline & $\alpha 1$ & & -0.01 \\
\hline & $\gamma 1$ & & 0.00 \\
\hline & $\beta 1$ & & 1.14 \\
\hline \multirow{5}{*}{ Australian Dollars } & $\begin{array}{r}\text { Mean } \\
\text { (constant) }\end{array}$ & $\mu$ & 1.40 \\
\hline & Variance & $\alpha 0$ & 749.96 \\
\hline & $\alpha 1$ & & $11,852.09$ \\
\hline & $\gamma 1$ & & $11,852.09$ \\
\hline & $\beta 1$ & & 517.28 \\
\hline \multirow{5}{*}{ Japanese Yen } & $\begin{array}{r}\text { Mean } \\
\text { (constant) }\end{array}$ & $\mu$ & 109.59 \\
\hline & Variance & $\alpha 0$ & $10,585.96$ \\
\hline & $\alpha 1$ & & \\
\hline & $\gamma 1$ & & \\
\hline & $\beta 1$ & & $99,435.49$ \\
\hline \multirow{5}{*}{ Brazilian Real } & $\begin{array}{r}\text { Mean } \\
\text { (constant) }\end{array}$ & $\mu$ & 3.51 \\
\hline & Variance & $\alpha 0$ & 0.05 \\
\hline & $\alpha 1$ & & 0.02 \\
\hline & $\gamma 1$ & & -0.01 \\
\hline & $\beta 1$ & & 0.92 \\
\hline \multirow{3}{*}{ Saudi Riyal } & $\begin{array}{r}\text { Mean } \\
\text { (constant) }\end{array}$ & $\mu$ & 0.27 \\
\hline & Variance & $\alpha 0$ & -2979.98 \\
\hline & $\beta 1$ & & 7879.58 \\
\hline
\end{tabular}




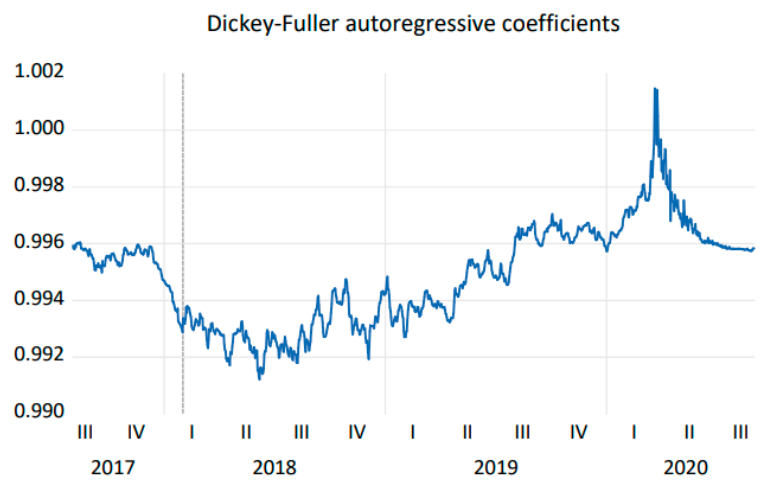

(a) Australian Dollar

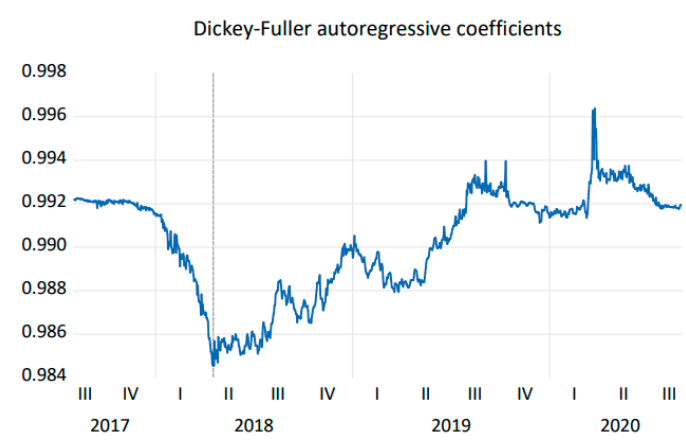

(c) British Pound

Dickey-Fuller autoregressive coefficients

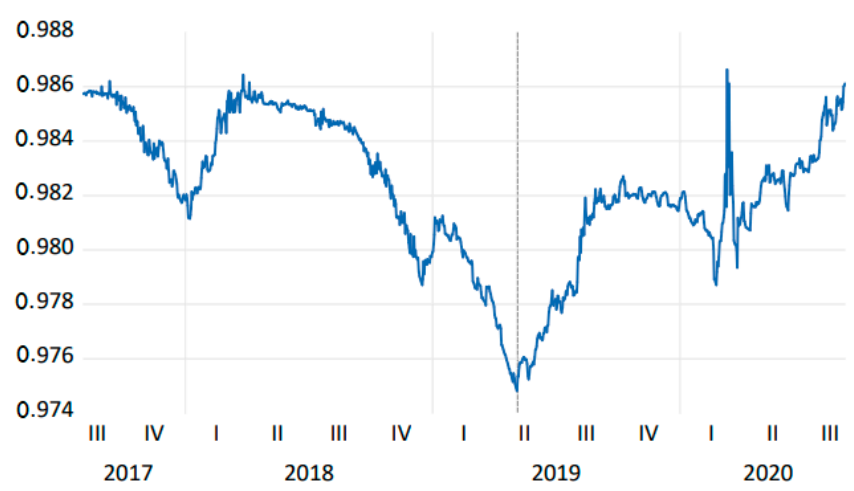

(e) Japanese Yen
Dickey-Fuller autoregressive coefficients

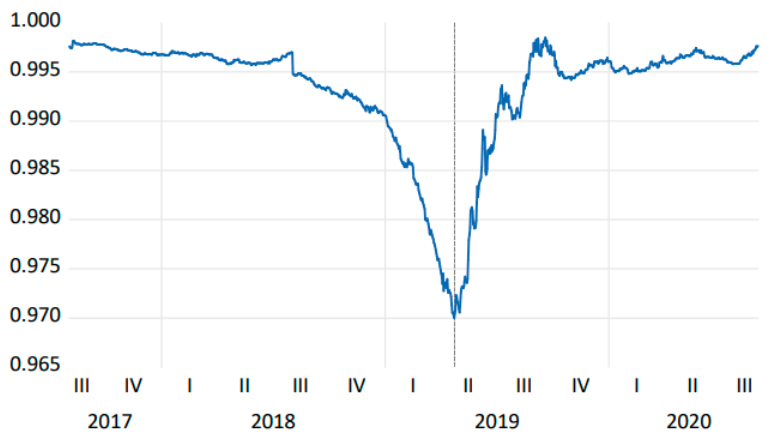

(b) Brazilian Real

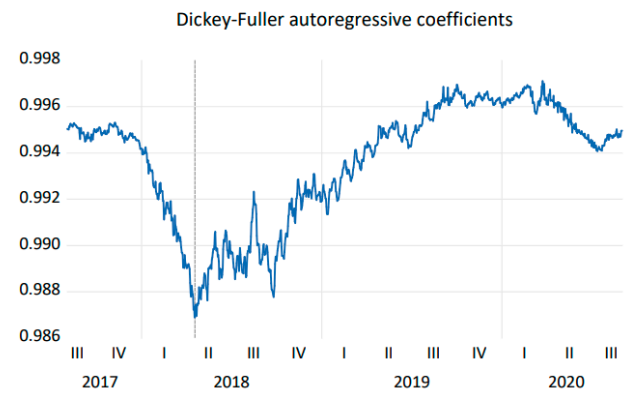

(d) European Euro

Dickey-Fuller autoregressive coefficients

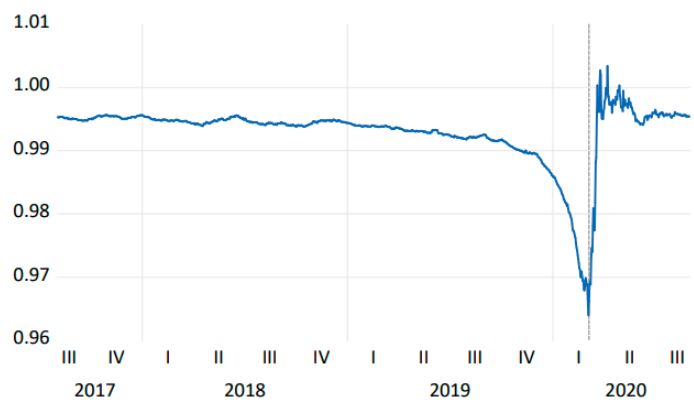

(f) Mexican Peso

Dickey-Fuller autoregressive coefficients

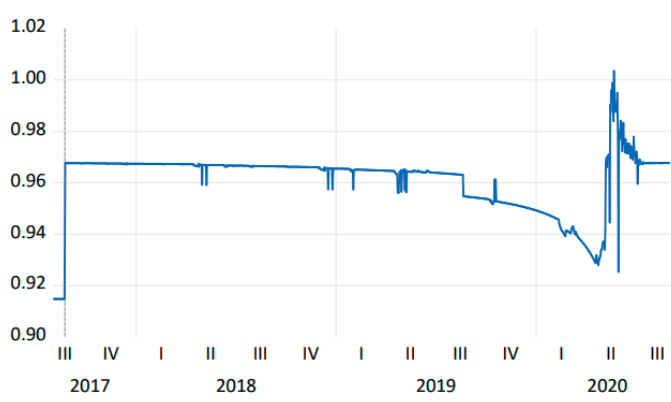

(g) Saudi Riyal

Figure 6. Dickey-Fuller autoregressive coefficients for seven FOREX Currencies. 


\subsection{Estimation of Asymmetric E-GARCH Volatility Persistence}

This part of the paper describes the outcomes derived from fitting asymmetric and symmetric return of the GARCH family models of Bitcoin currency and the U.S. traditional assets. This was implemented using Eviews. Tables 5-11 report the estimated coefficients obtained by EGARCH $(1,1)$ models.

Table 5. Estimated Result of E-GARCH Model for Australian Dollars Return Index during (2017-2020).

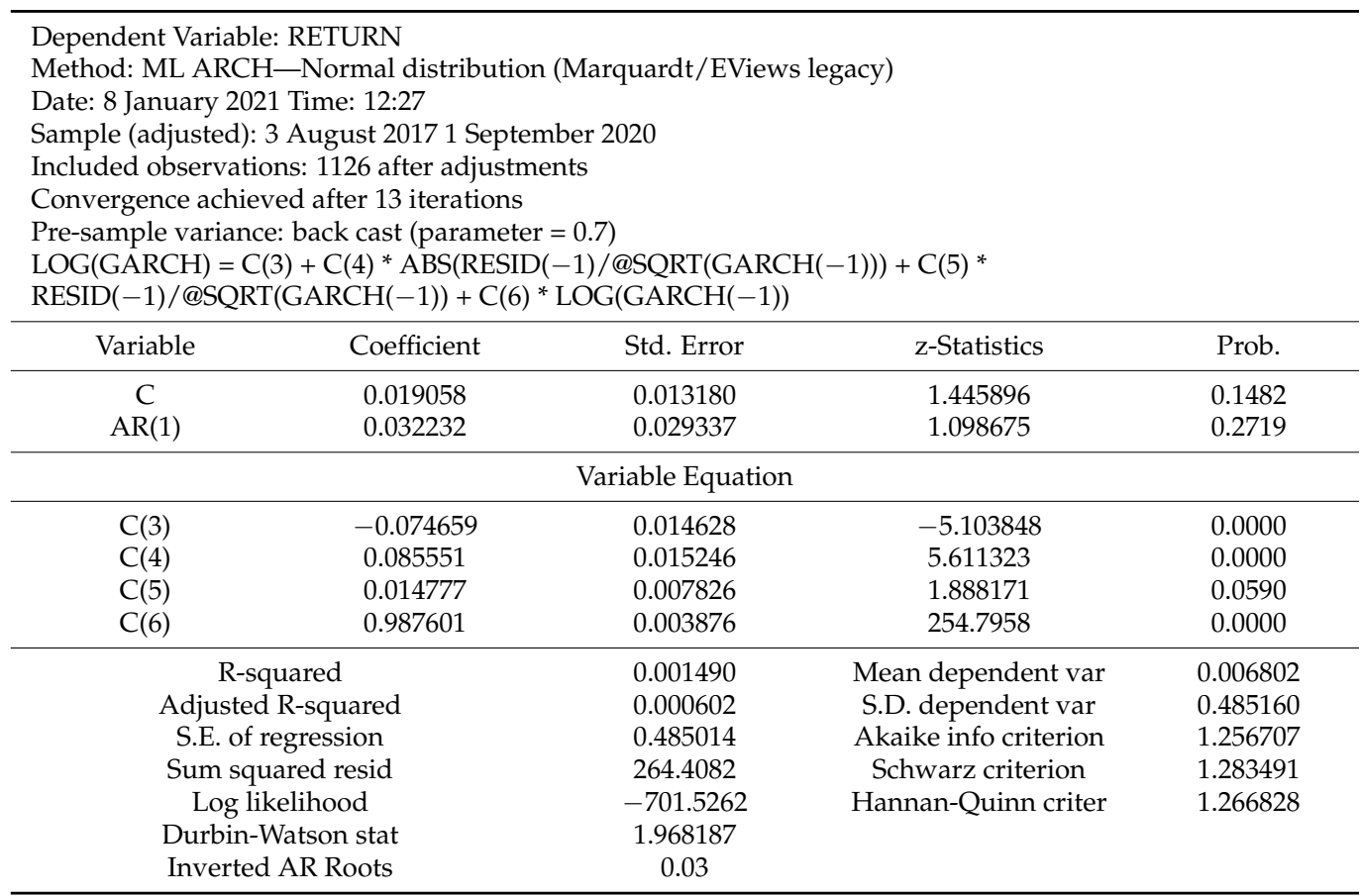

Table 6. Estimated Result of E-GARCH Model for Brazilian Real Return Index during (2017-2020).

\begin{tabular}{|c|c|c|c|c|}
\hline \multicolumn{5}{|c|}{$\begin{array}{l}\text { Dependent Variable: RETURN } \\
\text { Method: ML ARCH-Normal distribution (Marquardt/EViews legacy) } \\
\text { Date: } 8 \text { January } 2021 \text { Time: } 12: 32 \\
\text { Sample (adjusted): } 3 \text { August } 20171 \text { September } 2020 \\
\text { Included observations: } 1126 \text { after adjustments } \\
\text { Convergence achieved after } 24 \text { iterations } \\
\text { Pre-sample variance: back cast (parameter }=0.7) \\
\text { LOG(GARCH) }=\mathrm{C}(3)+\mathrm{C}(4) * \text { ABS }(\operatorname{RESID}(-1) / @ S Q R T(G A R C H(-1)))+\mathrm{C}(5) * \\
\text { RESID }(-1) / @ S Q R T(G A R C H(-1))+\mathrm{C}(6) * \text { LOG }(\mathrm{GARCH}(-1))\end{array}$} \\
\hline Variable & Coefficient & Std. Error & z-Statistics & Prob. \\
\hline $\begin{array}{c}\mathrm{C} \\
\operatorname{AR}(1)\end{array}$ & $\begin{array}{c}0.042660 \\
-0.008846\end{array}$ & $\begin{array}{l}0.021063 \\
0.042109\end{array}$ & $\begin{array}{c}2.025395 \\
-0.210083\end{array}$ & $\begin{array}{l}0.0428 \\
0.8336\end{array}$ \\
\hline \multicolumn{5}{|c|}{ Variable Equation } \\
\hline $\begin{array}{l}C(3) \\
C(4) \\
C(5) \\
C(6)\end{array}$ & $\begin{array}{l}-1.227251 \\
0.502782 \\
-0.051102 \\
-0.364374\end{array}$ & $\begin{array}{l}0.051303 \\
0.034177 \\
0.026985 \\
0.048036\end{array}$ & $\begin{array}{l}-23.92181 \\
14.71100 \\
-1.893696 \\
-7.585476\end{array}$ & $\begin{array}{l}0.0000 \\
0.0000 \\
0.0583 \\
0.0000\end{array}$ \\
\hline $\begin{array}{r}\text { Adj } \\
\text { S.E } \\
\text { Sun } \\
\text { L } \\
\text { Dur } \\
\text { Inv }\end{array}$ & $\begin{array}{l}\text { lared } \\
\text { ion } \\
\text { esid } \\
\text { od } \\
\text { stat } \\
\text { oots }\end{array}$ & $\begin{array}{c}0.000160 \\
-0.000730 \\
0.775111 \\
675.2965 \\
-1267.181 \\
2.069747 \\
-0.01\end{array}$ & $\begin{array}{l}\text { Mean dependent var } \\
\text { S.D. dependent var } \\
\text { Akaike info criterion } \\
\text { Schwarz criterion } \\
\text { Hannan-Quinn criter }\end{array}$ & $\begin{array}{l}0.024724 \\
0.774829 \\
2.261423 \\
2.288207 \\
2.271544\end{array}$ \\
\hline
\end{tabular}


Table 7. Estimated Result of E-GARCH Model for British Pound Return Index during (2017-2020).

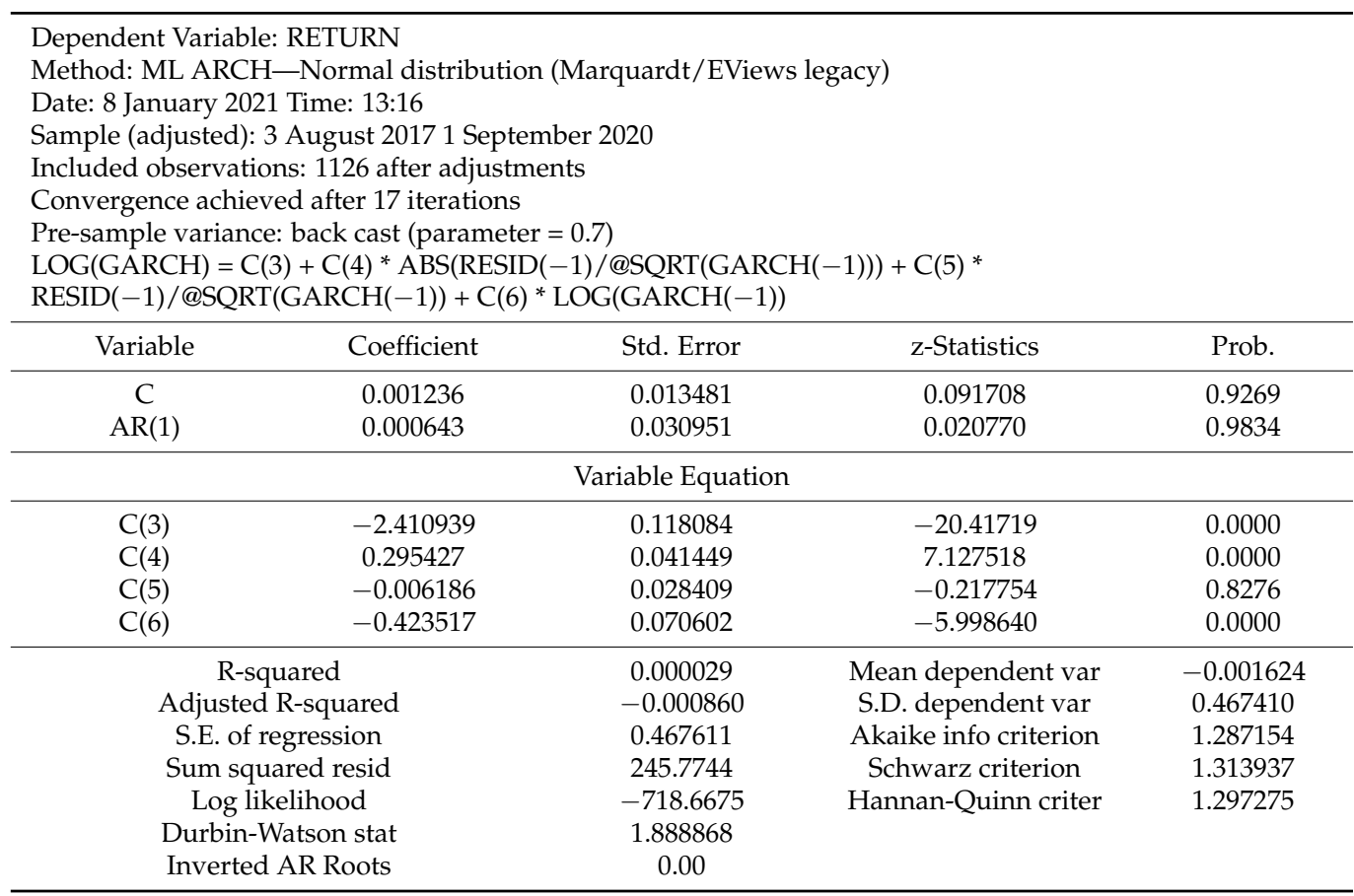

Table 8. Estimated Result of E-GARCH Model for Euro Return Index during (2017-2020).

\begin{tabular}{|c|c|c|c|c|}
\hline \multicolumn{5}{|c|}{$\begin{array}{l}\text { Dependent Variable: RETURN } \\
\text { Method: ML ARCH-Normal distribution (Marquardt/EViews legacy) } \\
\text { Date: } 8 \text { January } 2021 \text { Time: } 13: 18 \\
\text { Sample (adjusted): } 3 \text { August } 20171 \text { September } 2020 \\
\text { Included observations: } 1126 \text { after adjustments } \\
\text { Convergence achieved after } 13 \text { iterations } \\
\text { Pre-sample variance: back cast (parameter =0.7) } \\
\text { LOG }(G A R C H)=C(3)+C(4) * \text { ABS }(\operatorname{RESID}(-1) / @ S Q R T(G A R C H(-1)))+C(5) * \\
\text { RESID }(-1) / @ S Q R T(G A R C H(-1))+C(6) * \text { LOG }(G A R C H(-1))\end{array}$} \\
\hline Variable & Coefficient & Std. Error & z-Statistics & Prob. \\
\hline $\mathrm{C}$ & -0.002831 & 0.010908 & -0.259526 & 0.7952 \\
\hline $\mathrm{AR}(1)$ & 0.008867 & 0.032442 & 0.273307 & 0.7846 \\
\hline \multicolumn{5}{|c|}{ Variable Equation } \\
\hline $\mathrm{C}(3)$ & -2.897089 & 0.236316 & -12.25938 & 0.0000 \\
\hline $\mathrm{C}(4)$ & 0.186335 & 0.049557 & 3.760047 & 0.0000 \\
\hline $\mathrm{C}(5)$ & -0.070116 & 0.033627 & -2.085136 & 0.0371 \\
\hline$C(6)$ & -0.369807 & 0.116715 & -3.168454 & 0.0000 \\
\hline \multicolumn{2}{|c|}{ R-squared } & 0.000002 & Mean dependent var & -0.001184 \\
\hline \multicolumn{2}{|c|}{ Adjusted R-squared } & -0.000888 & S.D. dependent var & 0.365597 \\
\hline \multicolumn{2}{|c|}{ S.E. of regression } & 0.365759 & Akaike info criterion & 0.822749 \\
\hline \multicolumn{2}{|c|}{ Sum squared resid } & 150.3686 & Schwarz criterion & 0.849533 \\
\hline \multicolumn{2}{|c|}{ Log likelihood } & -457.2076 & Hannan-Quinn criter & 0.832870 \\
\hline \multicolumn{2}{|c|}{ Durbin-Watson stat } & 2.005011 & & \\
\hline \multicolumn{2}{|c|}{ Inverted AR Roots } & 0.01 & & \\
\hline
\end{tabular}

Table 5 presents the estimated result of EGARCH $(1,1)$, the model for forex currencies returns cryptocurrency. This implies that the asymmetric term's coefficient is positive (0.0147) and significant statistically at the $1 \%$ significance level. In exponential terms, C (5) indicates that for the FTSE, bad news has a larger effect on the forex currencies' volatility.

Table 6 illustrates the EGARCH $(1,1)$ estimated outcome of the model for forex currencies Brazilian real returns cryptocurrency of Bitcoin. The overall findings reveal higher leverage effects exist in the financial variables. This implies that the asymmetric term coefficient is negative $(-0.051)$ and significant statistically at the level of $1 \%$. In 
exponential terms, C (5) indicates that for the FTSE, bad news has a greater impact on forex market volatility.

Table 7 demonstrates the estimated result of EGARCH $(1,1)$, the model for FOREX currencies British pound returns cryptocurrency of Bitcoin. The overall findings reveal higher leverage effects exist in the FOREX markets. This reveals that the asymmetric term coefficient is negative $(-0.0061)$ and significant statistically at the $1 \%$ significance level. $C$ (5) illustrates, in exponential terms, that negative news is having a major impact on FTSE's volatility.

Table 9. Estimated Result of E-GARCH Model for Japanese Yen Return Index during (2017-2020).

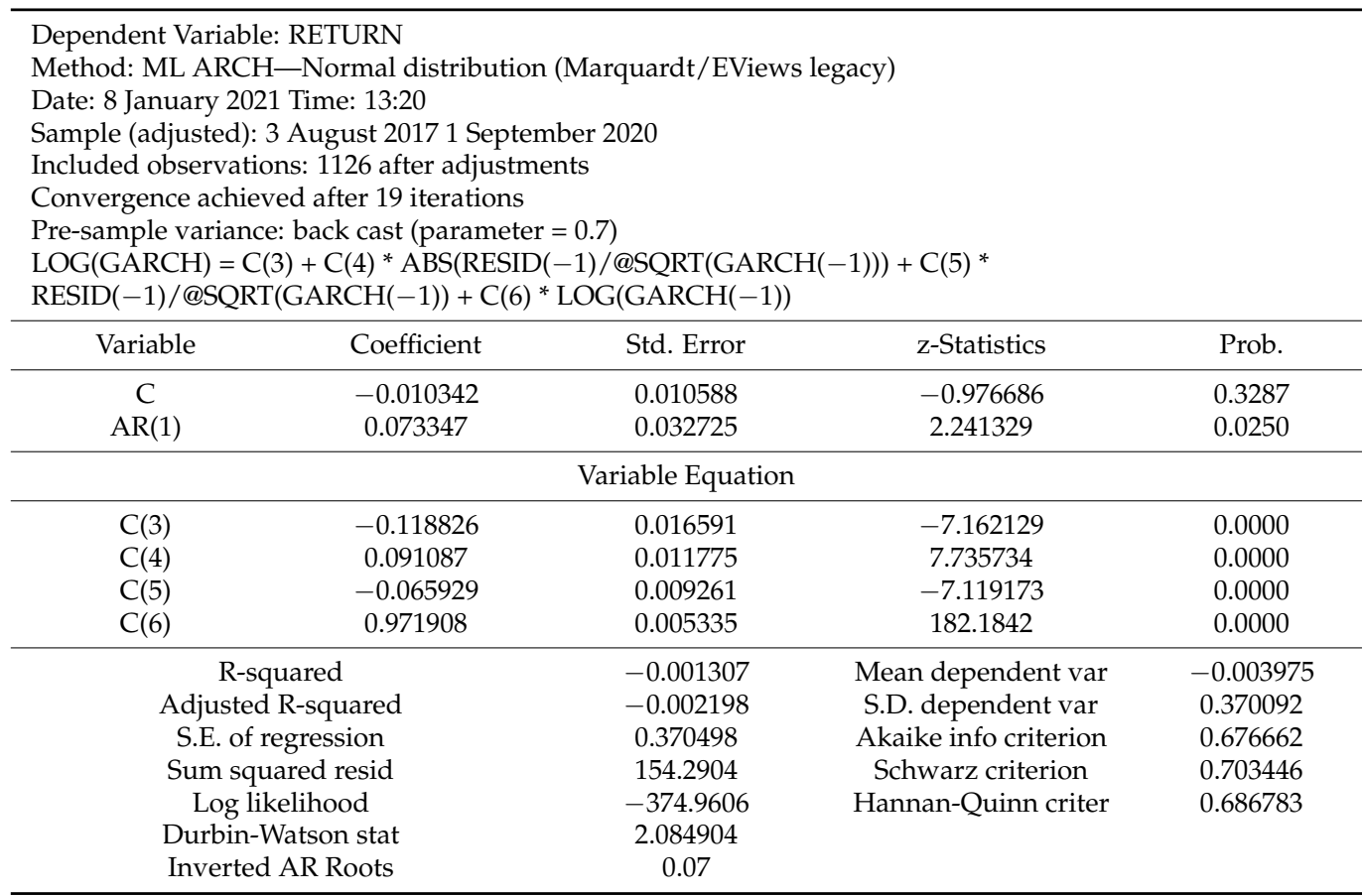

Table 10. Estimated Result of E-GARCH Model for Mexican Peso Return Index during (2017-2020).

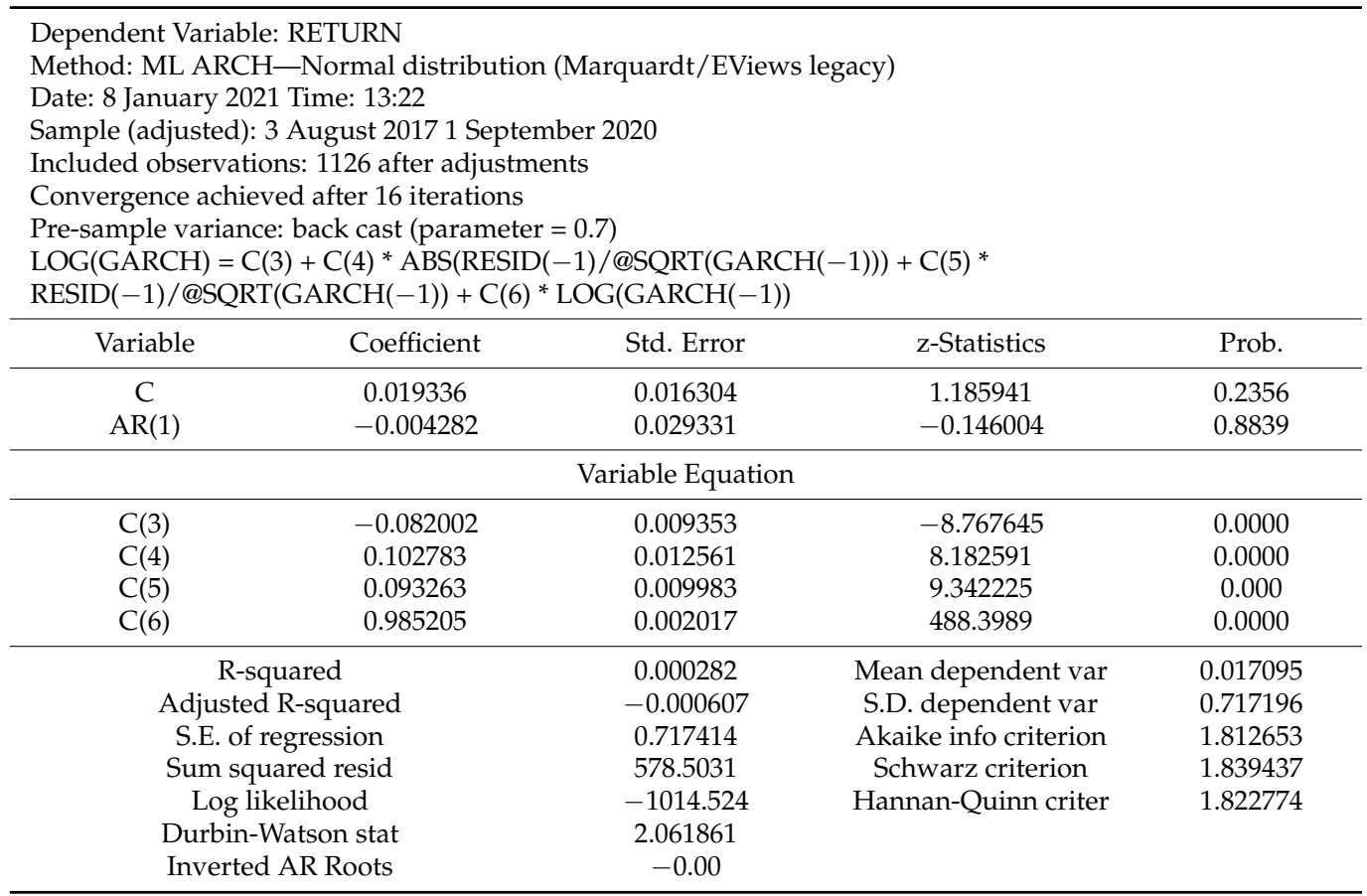


Table 11. Estimated Result of E-GARCH Model for Saudi Riyal Return Index during (2017-2020).

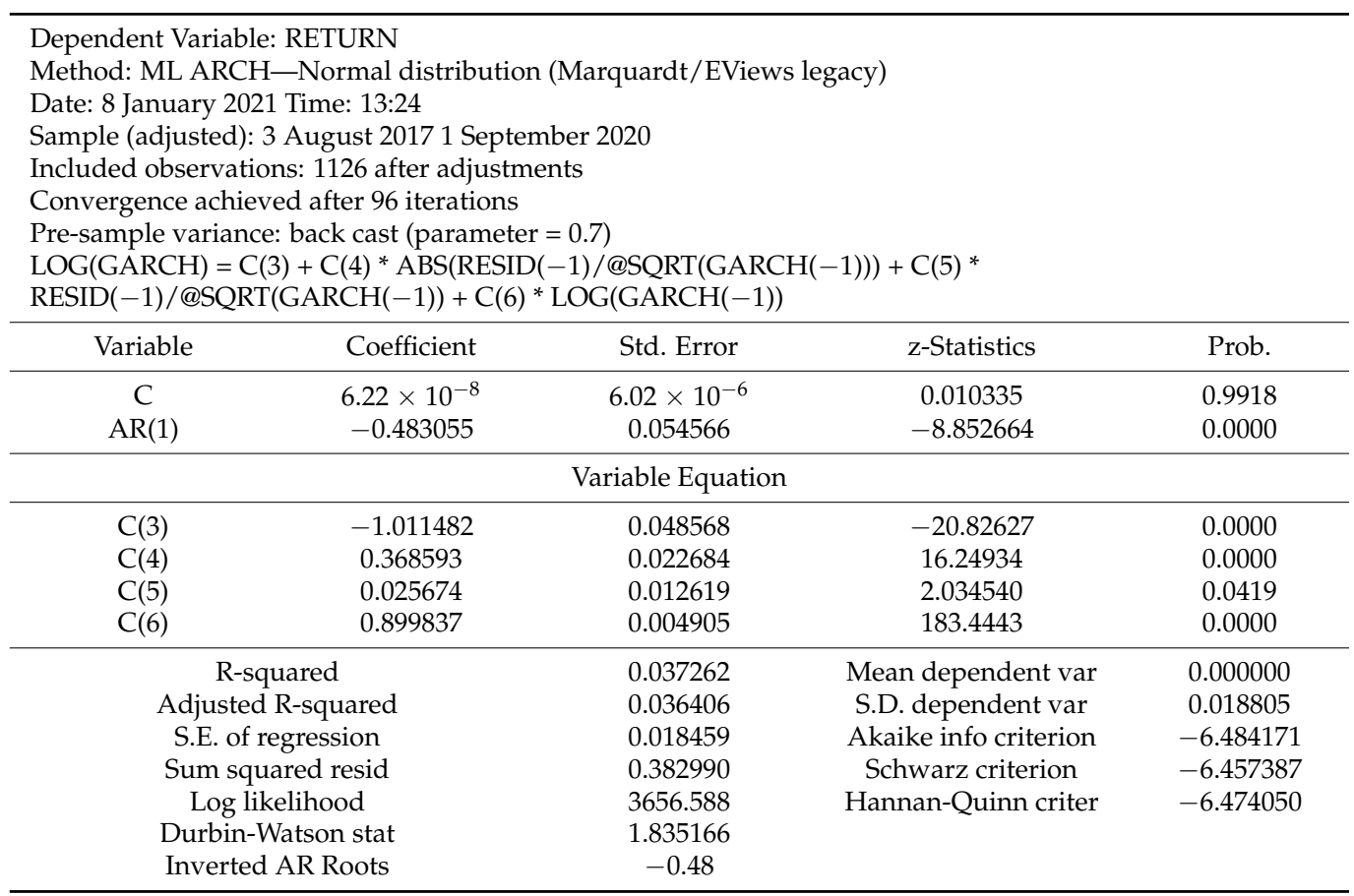

Table 8 depicts the estimated result of EGARCH $(1,1)$, a model for FOREX currencies British pound returns cryptocurrency of Bitcoin. In the currency markets, the aggregate results indicate larger leverage implications. This shows that the coefficient of the asymmetrical term is negative $(-0.070)$ and significant statistically at $1 \%$. In exponential terms, C (5) indicates that for the FTSE, the volatility of the currency market is more affected by unfavorable news.

Table 9 indicates the estimated result of EGARCH $(1,1)$, the model for FOREX currencies of the Japanese yen returns cryptocurrency of Bitcoin. Overall, the statistics indicate that the FOREX markets have larger leverage effects. This means that the asymmetric term's coefficient is negative $(-0.0659)$ and at the $1 \%$ level of significance it was significant statistically. In terms of exponentials, C (5) implies that unfavorable news has a greater impact on FOREX volatility for the FTSE.

Table 10 presents the estimated result of $\operatorname{EGARCH}(1,1)$, a model for FOREX currencies of Mexican peso returns cryptocurrency of Bitcoin. The aggregate findings show that the foreign exchange markets have larger leverage implications. This shows that the asymmetric term's coefficient is positive (0.0932) and at the $1 \%$ level, it was found that it is significant statistically. C (5) demonstrates that bad news has a bigger impact on the volatility of the FOREX markets for the FTSE than positive news.

Table 11 portrays the estimated result of EGARCH $(1,1)$, the model for FOREX currencies of Saudi riyal returns with the cryptocurrency of Bitcoin. In the currency markets, the aggregate results indicate stronger leverage implications. This implies that the asymmetric term's coefficient is positive $(0.0256)$ and at the $1 \%$ level, it was significant statistically. In exponential terms, C (5) indicates that for the FTSE, a combination of (samples from) normal distributions with different standard deviations might result in a heavy-tailed distribution.

Calculate the Volatility Cluster Probability

The artificial neural network, which processes with volatility clusters of a defined length, is utilized to check that measure of the likelihood of volatility clusters (equal to 796 data). The following is an example from that process training and testing instance. 
Table 12 depicts the result of the training phase with 796 samples in calculating the weight. Further test with remaining samples of 332 to predict the valid results. Table 13 illustrates the artificial neural network for selected input, output, and hidden layers with the covariates like Mexican Peso, British Pound, Australian Dollar, Japanese Yen, Brazilian Real, Saudi Riyal and EUR. The activation function to use for all units in the output layer was identity with hidden layer hyperbolic tangent function. Further, the rescaling method used for dependent variable date denotes the standardized variable.

Table 12. Training and Testing.

\begin{tabular}{|c|c|c|c|}
\hline \multicolumn{4}{|c|}{ Case Processing Summary } \\
\hline & & $\mathbf{N}$ & Percent \\
\hline \multirow{2}{*}{ Sample } & Training & 796 & $70.6 \%$ \\
\hline & Testing & 332 & $29.4 \%$ \\
\hline \multicolumn{2}{|c|}{ Valid } & 1128 & $100.0 \%$ \\
\hline \multicolumn{2}{|c|}{ Excluded } & 1 & \\
\hline \multicolumn{2}{|c|}{ Total } & 1129 & \\
\hline
\end{tabular}

Table 13. Network Information.

\begin{tabular}{|c|c|c|c|}
\hline \multirow{9}{*}{ Input Layer } & \multirow{7}{*}{ Covariates } & 1 & Mexican Peso \\
\hline & & 2 & British Pound \\
\hline & & 3 & Australian Dollar \\
\hline & & 4 & Japanese Yen \\
\hline & & 5 & Brazilian Real \\
\hline & & 6 & Saudi Riyal \\
\hline & & 7 & EUR \\
\hline & \multicolumn{2}{|c|}{ Number of Units ${ }^{a}$} & 7 \\
\hline & \multicolumn{2}{|c|}{ Rescaling Method for Covariates } & Standardized \\
\hline \multirow{3}{*}{ Hidden Layer(s) } & \multicolumn{2}{|c|}{ Number of Hidden Layers } & 1 \\
\hline & \multicolumn{2}{|c|}{ Number of Units in Hidden Layer $1^{\mathrm{a}}$} & 3 \\
\hline & \multicolumn{2}{|c|}{ Activation Function } & Hyperbolic tangent \\
\hline \multirow{5}{*}{ Output Layer } & Dependent Variables & 1 & Date \\
\hline & \multicolumn{2}{|c|}{ Number of Units } & 1 \\
\hline & \multicolumn{2}{|c|}{ Rescaling Method for Scale Dependents } & Standardized \\
\hline & \multicolumn{2}{|c|}{ Activation Function } & Identity \\
\hline & \multicolumn{2}{|c|}{ Error Function } & Sum of Squares \\
\hline
\end{tabular}

a Excluding the bias unit.

Figure 7 demonstrates the backpropagation neural network with the training of multilayer perceptron using the SPSS tool. This indicates that the input layer selected and the 50 layers are hidden this indicates darker the blue line and fatter line, in which fatter line denotes that there are positive impact, however, darker line indicates negative impact. These are the factors help predicting no defaults most efficiently. The error case in this model shows that it is strong. 


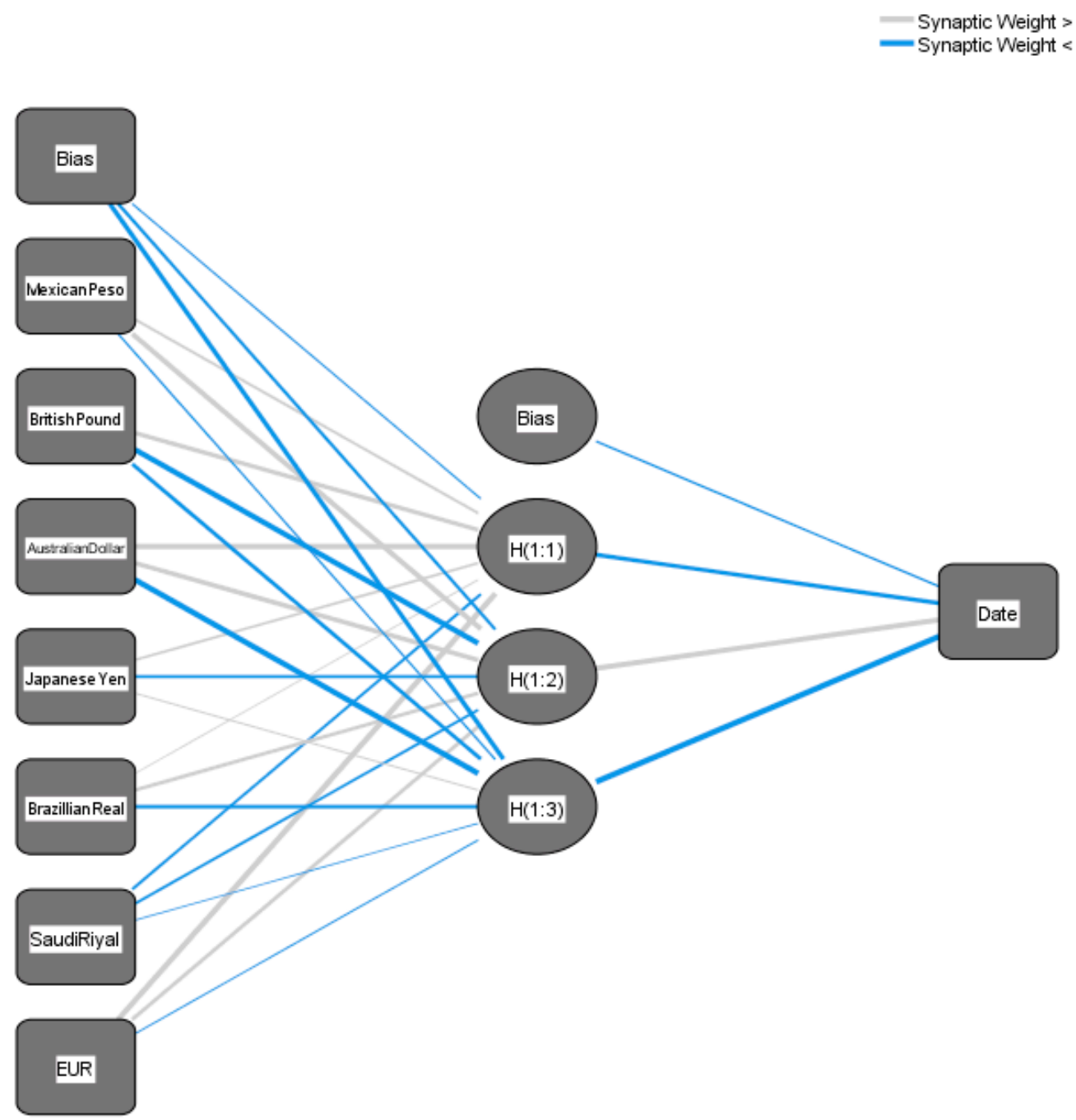

Figure 7. Function of backpropagation neural network.

Table 14 illustrates the model summary of training and testing cases. In this multilayer perceptron neural network, the sum of squares error predicted value is 10.633. The Stopping rules subcommand specifies the rules that determine when to stop training the neural network, which takes one consecutive step with no decrease in error. In this operational process, it takes only 7 seconds to complete the training process. The output shows input fields, synaptic weights, hidden layer and output categories representing misstated 'yes' and 'no'.

Table 14. Model Summary.

\begin{tabular}{|c|c|c|}
\hline \multirow{4}{*}{ Training } & Sum of Squares Error & 10.633 \\
\hline & Relative Error & 0.027 \\
\hline & Stopping Rule Used & $\begin{array}{l}1 \text { consecutive step(s) with no } \\
\text { decrease in error }{ }^{\text {a }}\end{array}$ \\
\hline & Training Time & 0:00:00.07 \\
\hline \multirow{2}{*}{ Testing } & Sum of Squares Error & 5.269 \\
\hline & Relative Error & 0.036 \\
\hline & Dependent Variable: Date & \\
\hline
\end{tabular}




\section{Conclusions}

The high volatility of cryptocurrency exchange rates is one of their most distinguishing features. The author has found that a volatility cluster process creates a sequence of volatility with a major exponent of Hurst. Using the Hybrid Technique (E-GARCH-NN) of its related volatility series, this research paper presented a unique methodology for calculating the likelihood of a series' volatility clusters. For cryptocurrencies and FOREX currencies, the researcher used daily starting and closing prices for roughly four years to analyse the data using five properties: centrality, volatility, robustness, risk, and clustering structure. The result obtained from the comparative analysis of the two different financial assets, is illustrated. Volatility is projected for 5 days ahead of time, and the values are compared to the actual values to determine the accomplishment of the volatility forecasting models. In comparison to Bitcoin, the data demonstrate that FOREX markets have significantly different volatility patterns and dynamics. The FOREX markets seem much more volatile, and their distributions require more tails and biases. This has significant consequences for risk modelling and calculation in these markets.

The research was conducted to examine the predictive efficiency using one hidden layer of competitive multilayer ANN perceptron architecture. For training the ANNs and evaluating their predicting ability, a backpropagation technique was implemented. The probability of a Euro/Australian dollar volatility cluster was, therefore, determined to be much lower. Bitcoin/British Pound, Ethereum/Euro, and Tether with other foreign currencies, on the other hand, have a similar profile, with the likelihood of volatility clusters for all three traditional assets (equities, bonds, and cash) being considerably higher. As a consequence, the outcomes display that cryptocurrency volatility varies faster than traditional assets and considerably faster than forex pairs. The asymmetric reaction of the FOREX market return volatility was found to be statistically significantly responsive to good news than negative news in the global financial market.

Funding: This research received no external funding.

Institutional Review Board Statement: Not Applicable.

Informed Consent Statement: Not Applicable.

Data Availability Statement: Not Applicable.

Conflicts of Interest: The authors declare no conflict of interest.

\section{References}

Alaminos, David, Rafael Becerra-Vicario, Manuel Á Fernández-Gámez, and Ana Cisneros J. Ruiz. 2019. Currency crises prediction using deep neural decision trees. Applied Sciences 9: 5227. [CrossRef]

Altan, Aytac, Seçkin Karasu, and Stelios Bekiros. 2019. Digital currency forecasting with chaotic meta-heuristic bio-inspired signal processing techniques. Chaos, Solitons \& Fractals 126: 325-36.

Arellano, Miguel Ataurima, and Gabriel Rodriguez. 2020. Empirical modeling of high-income and emerging stock and Forex market return volatility using Markov-switching GARCH models. The North American Journal of Economics and Finance 52 : 101163. [CrossRef]

Asai, Manabu, Rangan Gupta, and Michael McAleer. 2020. Forecasting volatility and co-volatility of crude oil and gold futures: Effects of leverage, jumps, spillovers, and geopolitical risks. International Journal of Forecasting 36: 933-48. [CrossRef]

Belasen, Ariel R., and Riza Demirer. 2019. Commodity-currencies or currency-commodities: Evidence from causality tests. Resources Policy 60: 162-68. [CrossRef]

Catania, Leopoldo, and Tommaso Proietti. 2020. Forecasting volatility with time-varying leverage and volatility of volatility effects. International Journal of Forecasting 36: 1301-17. [CrossRef]

Cho, Jae-Beom, Hong-Ghi Min, and Judith Ann McDonald. 2020. Volatility and dynamic currency hedging. Journal of International Financial Markets, Institutions and Money 64: 101163. [CrossRef]

Dritsaki, Chaido. 2019. Modeling the Volatility of Exchange Rate Currency using GARCH Model. Economia Internazionale/International Economics 72: 209-30.

Ho, Kin-Yip, Yanlin Shi, and Zhaoyong Zhang. 2017. Does news matter in China's foreign exchange market? Chinese RMB volatility and public information arrivals. International Review of Economics $\mathcal{E}$ Finance 52: 302-21. 
Katusiime, Lorna. 2019. Investigating spillover effects between foreign exchange rate volatility and commodity price volatility in Uganda. Economies 7: 1. [CrossRef]

Kim, Alisa, Simon Trimborn, and Wolfgang K. Härdle. 2019. VCRIX-a Volatility Index for Crypto-Currencies. Berlin: Humboldt-Universität zu Berlin.

Kočenda, Evžen, and Michala Moravcová. 2019. Exchange rate comovements, hedging and volatility spillovers on new EU forex markets. Journal of International Financial Markets, Institutions and Money 58: 42-64. [CrossRef]

Koosakul, Jakree, and Iihyock Shim. 2021. The effects of asset price volatility on market participation: Evidence from the Thai foreign exchange market. Journal of Banking E Finance 124: 106036.

Liu, Ruipeng, Riza Demirer, Rangan Gupta, and Mark Wohar. 2020. Volatility forecasting with bivariate multifractal models. Journal of Forecasting 39: 155-67. [CrossRef]

Maciel, Leandro dos Santos, and Rosangela Ballini. 2017. Value-at-risk modeling and forecasting with range-based volatility models: Empirical evidence. Revista Contabilidade E Finanças 28: 361-76.

McAleer, Michael, and Christian M. Hafner. 2014. A one line derivation of EGARCH. Econometrics 2: 92-97. [CrossRef]

Nelson, Daniel B. 1991. Conditional Heteroskedasticity in Asset Returns: A New Approach. Modelling Stock Market Volatility 59: 347-70. [CrossRef]

Nikolova, Venelina, Juan E. Trinidad Segovia, Manuel Fernández-Martínez, Martinez Angel Sánchez-Granero, Trinidad Segovia, Manuel Fernández-Martínez, and Miguel Angel Sánchez-Granero. 2020. A Novel Methodology to Calculate the Probability of Volatility Clusters in Financial Series: An Application to Cryptocurrency Markets. Mathematics 8: 1216. [CrossRef]

Pongsena, Watthana, Prakaidoy Ditsayabut, Nittaya Kerdprasop, and Kittisak Kerdprasop. 2018. An Analysis of the Co-movement of Price Change Volatility in Forex Market. Paper presented at the World Congress on Engineering, London, UK, July 4-6.

Ramos-Pérez, Eduardo, Pablo J. Alonso-González, and José Javier Núñez-Velázquez. 2019. Forecasting volatility with a stacked model based on a hybridized Artificial Neural Network. Expert Systems with Applications 129: 1-9. [CrossRef]

Reus, Lorenzo, José A. Carrasco, and Pablo Pincheira. 2020. Do it with a smile: Forecasting volatility with currency options. Finance Research Letters 34: 101251. [CrossRef]

Rognone, Lavinia, Stuart Hyde, and Sarah S. Zhang. 2020. News sentiment in the cryptocurrency market: An empirical comparison with Forex. International Review of Financial Analysis 69: 101462. [CrossRef]

Salisu, Afees A., Oluwatomisin J. Oyewole, and Ismail O. Fasanya. 2018. Modelling return and volatility spillovers in global foreign exchange markets. Journal of Information and Optimization Sciences 39: 1417-48. [CrossRef]

Samirkaş, Mustafa Can. 2020. Modeling and Forecasting Volatility of Bitcoin. Management E Economics 15: 263.

Segovia, J. E. Trinidad, M. Fernández-Martínez, and M. A. Sánchez-Granero. 2019. A novel approach to detect volatility clusters in financial time series. Physica A: Statistical Mechanics and Its Applications 535: 122452. [CrossRef]

$\mathrm{Su}$, Fei. 2021. Conditional volatility persistence and volatility spillovers in the foreign exchange market. Research in International Business and Finance 55: 101312. [CrossRef]

Swapna, Ch Swetha, V. V. Kumar, and J. V. R. Murthy. 2015. A New Approach to Cluster Datasets without Prior Knowledge of Number of Clusters. Journal of Scientific and Industrial Research 74: 2015.

Tan, Shay-Kee, Kok-Haur Ng, Jennifer So-Kuen Chan, and Ibrahim Mohamed. 2019. Quantile range-based volatility measure for modelling and forecasting volatility using high frequency data. The North American Journal of Economics and Finance 47: 537-51. [CrossRef]

Wen, Tiange, and Gang-Jin Wang. 2020. Volatility connectedness in global foreign exchange markets. Journal of Multinational Financial Management 54: 100617. [CrossRef] 